\title{
EDAD SEXUAL Y EXCLUSIÓN DE LA RESPONSABILIDAD PENAL. FUNDAMENTOS DEL DERECHO ANGLOSAJÓN
}

\author{
Amparo Martínez Guerra ${ }^{1}$ \\ Title: Sexual age and exemption from criminal \\ responsibility. Fundamentals of Common Law Systems
}

\begin{abstract}
Resumen: En los últimos años, la protección de menores frente comportamientos de abuso y explotación sexual ha sido una de las preocupaciones principales en los sistemas legales de Derecho continental y anglosajón. La respuesta de los Legisladores penales ha sido la elevación de la edad de consentimiento sexual de los menores de edad. Sin embargo, la medida provoca problemas interpretativos de índole constitucional que no pueden ser obviados. Por un lado, la posible afectación del derecho fundamental a la privacidad de los propios menores (desarrollo de su sexualidad). Por otro, la proporcionalidad de la sanción penal prevista para ese tipo de delitos, así como los efectos de la inscripción en los Registros de Delincuentes sexuales. En España, la modificación de la LO 1/2015, de 30 de marzo, elevó la edad de consentimiento sexual a los 16 años. La reforma también incluyó el nuevo art. 183 quáter, que permite al Tribunal eximir de responsabilidad penal cuando autor y víctima sean «próximos por edad y grado de desarrollo o madurez». En los sistemas
\end{abstract}

\footnotetext{
1 Profesora Ayudante Doctora (acre. Titular) Universidad Complutense de Madrid. Email: ampmarti@ucm.es. Este trabajo ha sido realizado en el marco del I+D DER201677228-P, Víctimas de delitos: Modelos de actuación integral (IP María del Mar Carrasco Andrino, Universidad de Alicante) y del Proyecto Emergente GV/ 2019/ 061, Victimización del menor y la relevancia de su consentimiento en los delitos contra la indemnidad sexual y la intimidad (IP María del Mar Moya Fuentes, Universidad de Alicante). Una parte de los resultados de este estudio fueron presentados como ponencia en el Congreso Internacional sobre víctimas de delitos: nuevas y viejas formas de victimización en el s. XXI, celebrado los días 6, 7 y 8 de noviembre de 2019 en la Universidad de Alicante. Agradezco especialmente los comentarios y observaciones de la profesora Ana Carazo Johanning (Universidad Internacional de la Florida).
} 
penales anglosajones esta cláusula, denominada «cláusula de escape»o "cláusula Romeo y Julieta», es una de las piezas centrales del delito del statutory rape o delito de violación definido por estatuto.

Este artículo examina los orígenes, configuración y el fundamento de la exclusión de la responsabilidad penal por «cercanía en edad o desarrollo» en los Estados Unidos de América (sistemas federal y estatal), Reino Unido e Irlanda del Norte, República de Irlanda y Canadá. El artículo analiza también la jurisprudencia más importante al respecto y los problemas constitucionales derivados de las nuevas las edades de consentimiento.

Abstract: In recent years the protection of minors against sexual abuse and exploitation has been one of the main concerns in the Civil and Common Law legal systems. The response of the Criminal Legislators has been the raise of the age of sexual consent of minors. However, this measure causes constitutional problems that cannot be ignored. On the one hand, the conflict with the minor fundamental right of privacy (development of the sexuality). On the other hand, the proportionality of the criminal sanction provided for such crimes, as well as the effects of the registration in the Sex Offenders Registry. In Spain, the amendment introduced by the Organic Law 1/2015, of March 30, raised the age of sexual consent to 16 years. The Law created the new article 183 quater in the Criminal Code to allow the Court to exempt from criminal responsibility when the defendant and the victim are "close in age and development or maturity». In Common Law criminal systems that clause, called «escape clause» or «Romeo and Juliet clause» is one of the central pieces of the statutory rape.

This article examines the origins, the elements and the rationale of the exclusion of criminal responsibility for «close in age and development» in the United States of America (federal and state law), the United Kingdom and Northern Ireland, Ireland and Canada. The article analyses the most important case-law regarding the constitutional problems arising from the new ages of consent.

Palabras clave: menores, consentimiento, abuso sexual, antijuridicidad, justificación, error de hecho, cláusula Romeo Julieta, Sistemas legales anglosajones, Derecho penal.

Keywords: minors, consent, statutory rape, unlawfulness, defenses, mistake of fact, Common Law Legal Systems, Criminal Law.

\section{Planteamiento}

La SAP de Navarra 873/2018, de 26 de septiembre de 2018 estableció los siguientes hechos probados ${ }^{2}$ :

2 SAP de Navarra (Secc. $1^{\text {a) }}$ 873/2018, de 26 de septiembre de 2018. 
"El acusado Javier nacido en 1995 sin antecedentes penales, de nacionalidad peruana, llegó a España en el mes de septiembre de 2015, en donde se encontraba su madre, con quien pasó a residir de forma habitual, obteniendo su residencia legal en España. Al llegar aquí conoció a su prima María Esther, nacida en 2003, que había venido a España seis meses antes de que lo hiciera Javier, para estar con su madre Lucía, que estaba ya residiendo en España. Derivada de esa relación de parentesco pues las madres de ambos eran hermanas, se veían habitualmente. En los meses de noviembre y diciembre de 2016 aproximadamente empezó un mayor contacto entre el acusado Javier y la menor María Esther, a instancias de ésta, que con la excusa de que le ayudara a hacer las tareas escolares se dirigía al domicilio donde vivía el acusado Javier con la intención de verlo, porque le gustaba, lo que llevó a cabo de forma reiterada. Javier en esos momentos vivía con su madre Florencia, y el marido de ésta en el domicilio de esta ciudad. Un día no suficientemente determinado, pero en la segunda quincena del mes de diciembre de 2016, la menor María Esther acudió, como lo hacía habitualmente, al domicilio de Javier y estando ambos juntos, ella le empezó a besar y acariciar, situación que llevó de forma voluntaria a María Esther a tener relaciones sexuales con Javier, que consistieron en penetración vaginal, pese a que Javier, en un inicial momento intentó rechazar dicha relación, relación sexual que tuvieron sin protección al decirle María Esther que ya utilizaba pastillas. A consecuencia de esa relación sexual María Esther quedó embarazada, lo que se constató a partir de la asistencia ginecológica que le fue prestada en fecha 23 de enero de 2017 en el Servicio de Ginecología del Centro de Atención a la Mujer del II Ensanche de Pamplona, teniendo el embrión 7 semanas de evolución, siendo sometida a una interrupción voluntaria del embarazo por el procedimiento de legrado evacuador mediante aspiración el día 1 de febrero de 2017, detectándose en los restos abortivos un perfil genético compatible con el del acusado. Doña Lucía, madre de María Esther, después de formular inicial denuncia en representación legal de su hija menor María Esther compareció ante el juzgado en fecha 2 de febrero de 2017 y manifestó su deseo de retirar la denuncia en su día formulada solicitando el archivo de la causa manifestando que su hija había reconocido sus errores, que el denunciado de su sobrino y que no quería romper lazos familiares. Con anterioridad a estos hechos la menor María Esther ya había tenido relaciones sexuales después de haber llegado a España, habiendo indicado que a los 11 años habia comenzado a tener relaciones sexuales en su país de origen».

La relevancia del fallo radica en que el Tribunal consideró que, en el caso concreto, se cumplían los requisitos de proximidad en edad, desarrollo y madurez exigidos por el art. 183 quáter CP para poder aplicar la exclusión de la responsabilidad penal del autor. Para ello, la AP de Navarra examinó condiciones personales, sociales, sexuales e incluso económicas, tanto de la víctima como del acusado, algo que, en principio, el propio Tribunal Supremo, especialmente con respecto a la víctima, había desaconsejado, al entender que la regulación establece una presunción ius et de iure y no permite, «en principio, indagar las condiciones del menor para confirmar la existencia de esa capacidad que la Ley considera incompleta» ${ }^{3}$.

\footnotetext{
3 Véase por todas, la STS 287/2018, de 14 de junio (Ponente Berdugo de la Torre).
} 
La AP de Navarra entendió que en el caso concreto existía proximidad en edad, a pesar de que en el momento de comisión de los hechos la diferencia de edad fuera de 8 años (13 años y 9 meses la mujer y 21 el varón) o mejor dicho, que los 8 años de diferencia no excluían la proximidad. Con respecto a la menor, analizó su declaración en la que afirmaba que "se sentía atraída por su primo», que «nadie presionó a nadie» y que «no hubo acoso por parte de él». También valoró el hecho de que la menor afirmara haber tenido relaciones de naturaleza sexual previas con otras personas desde los 11 años. Además tomó en consideración el hecho de que, por ni por su aspecto físico, ni por sus respuestas, la víctima aparentara una especial madurez superior a su edad ${ }^{4}$, «ni tampoco claramente superior al de la persona con la que mantuvo la relación sexual, cuando además queda acreditado que la menor ya había tenido relaciones sexuales con otras personas. Por último, se trata de unos jóvenes que tenían, al parecer, similares formas de entretenimiento, concepto cultural, formación y situación socio económica, y que las relaciones del acusado se circunscribian al ámbito exclusivamente familiar». Todo ello permitió concluir al Tribunal que «se aprecia que sus posiciones en la relación sexual mantenida son de aparente proximidad en cuanto al grado de desarrollo o madurez, no existiendo, al menos, diferencias sustanciales que pudiera a priori representar la edad, dada la madurez y circunstancias concurrentes antes indicadas entre el acusado y la menor, y que por tanto el consentimiento libre que prestó la menor tiene la suficiencia a que se refiere el artículo 183 quáter del $C P »$ (FJ. Cuarto).

Desde la entrada en vigor de la LO 1/2015, de 30 de marzo, las sentencias que se han pronunciado sobre hechos similares se han centrado en el enjuiciamiento de conductas cometidas por mayores de edad penal y menores de edad sexual. Las líneas de análisis jurisprudencial son dos. Por un lado, el examen de la concurrencia de error de tipo relativo a la edad de la víctima o de prohibición con respecto a la norma. Por otro, la aplicación de la cláusula de exclusión de la responsabilidad penal del art. 183 quáter CP y, por lo tanto, el análisis de los elementos de «proximidad en edad y grado de desarrollo o madurez del autor». En este aspecto, como la mayoría de los fallos se refieren a hechos cometidos con anterioridad a la entrada en vigor del art. 183 quáter $\mathrm{CP}$, el Tribunal Supremo ha venido resolviendo los recursos de casación por infracción de ley (art. 849.1 LECRIM) relativos a la aplicación de ese precepto a través del art. 2.2 CP (principio de retroactividad de la ley penal más favorable) $)^{5}$. Sólo algunos pronuncia-

4 El aspecto de la valoración de la declaración de la menor de edad es muy relevante porque la prestó ante la Policía cuando tenía 13 años. Sin embargo, no lo hizo durante la fase de instrucción y volvió a hacerlo en el acto del juicio oral cuando ya contaba con 15 años.

5 Véanse, por ejemplo, ATS 67/2016, de 21 de enero de 2016 (Ponente Marchena Gómez); STS 782/2016, de 19 de octubre (Ponente Marchena Gómez), STS 946/2016, de 15 de diciembre (Ponente: Monterde Ferrer); STS 1001/2016, de 18 de enero de 2017 
mientos muy recientes de Tribunales inferiores abordan el enjuiciamiento de hechos cometidos con posterioridad al cambio normativo ${ }^{6}$.

La cláusula de exclusión de la responsabilidad penal contenida en el art. 183 quáter $\mathrm{CP}$ es resultado de la transposición del art. 8 de la Directiva 2011/93/UE, del Parlamento Europeo y del Consejo, de 13 de diciembre de 2011, relativa a la lucha contra los abusos sexuales y la explotación sexual de los menores y la pornografía infantil y por la que se sustituye la Decisión Marco 2004/68/JAI del Consejo ${ }^{7}$. Ese precepto establece la facultad de los Estados Miembros para decidir si algunas modalidades puede ser consideradas "actos de carácter sexual consentidos entre personas próximas por edad y grado de desarrollo o madurez física y psicológica, siempre que los actos no impliquen abusos ${ }^{8}$.

En el Derecho penal anglosajón esa misma cláusula, conocida como "age differential between the victim and the defendant», "escape clause» $O$ "Romeo and Juliet clause» ha sido tradicionalmente una pieza esencial en la regulación de los delitos sexuales en sentido amplio. La exposición de sus orígenes, sus elementos fundamentales, funcionamiento y su evolución jurisprudencial a lo largo de décadas, puede ayudar a interpretar el contenido de un precepto novedoso en nuestro Ordenamiento, pero con larga tradición en otros sistemas jurídico penales.

Este trabajo tiene como finalidad exponer y analizar el contenido y funcionamiento del equivalente a la cláusula de exclusión de la responsabilidad penal del art. 183 quáter CP en los Estados Unidos de América (nivel federal y estatal), Reino Unido, Irlanda y Canadá. Para ello, se realiza un estudio sistemático de los códigos o leyes penales correspondientes y

(Saavedra Ruiz); ATS 601/2017, de 23 de marzo (Ponente: Soriano Soriano); STS 58/2017, de 7 de febrero de 2017 (Conde-Pumpido Tourón).

6 En algunos pronunciamientos de instancia la cercanía entre la sentencia de la AP y la entrada en vigor de la reforma de la LO 1/2015, de 30 de marzo, es mínima. En casos como la SAP de Jaén (Sec. Segunda) 151/2015, de 11 de mayo de 2015 la reforma ya había sido incluso publicada en el Boletín Oficial del Estado y se encontraba en periodo de vacatio legis; SAP La Coruña 183/2019, de 22 de abril; SAP Asturias 28/2019, de 17 de julio; SAP Sevilla (Secc. Tercera) de 22 de octubre de 2019. Para análisis de los elementos de todos estos fallos, así como la SAP Navarra (Secc. $1^{\text {a) }}$ 873/2018, de 26 de septiembre de 2018 véase, Martínez GuerRA, A., «El artículo 183 quáter CP. Problemas interpretativos de una cláusula importada», en VV.AA., Víctimas de delitos: Modelos de actuación integral, Tirant lo blanch, Valencia, 2020, pp. 133-16o.

7 Doue L 335, 17/12/2011, p. 1-14, con fecha de transposición al Derecho nacional el 18/12/2013 (art. 27).

8 Las modalidades son las contenidas en el art. 3.2 y 3.4 de la Directiva. La primera de ellas, "hacer, con fines sexuales, que un menor que no ha alcanzado la edad de consentimiento sexual presencie actos de carácter sexual, aunque no participe en ellos». La segunda, «realizar actos de carácter sexual con un menor que no ha alcanzado la edad de consentimiento sexual». Repárese en el hecho de que la última parte de la previsión («siempre que los actos no impliquen abusos») no ha sido transpuesta por el Legislador español. 
así como de la jurisprudencia más relevante en la materia. En el caso de los Estados Unidos de América, se estudia también el importante cambio jurisprudencial que han supuesto las decisiones de su Tribunal Supremo en Esquivel-Quintana v. Session, Attorney General (2017) y del Tribunal Supremo de Alaska en John Doe v. State of Alaska, Department of Public Safety (2019). Ambos fallos, a pesar de su diferente naturaleza y origen, impactan de manera decisiva en dos consecuencias asociadas a la condena por modalidades equivalentes a nuestro abuso sexual cuando estamos antes personas próximas en edad y desarrollo y madurez. El fallo del Tribunal Supremo de los Estados Unidos se pronuncia sobre la expulsión del territorio de residentes extranjeros por la comisión de estos delitos. El del Tribunal Supremo de Alaska, sobre la constitucionalidad lo hace sobre el alcance y los efectos de la inscripción en los registros de delincuentes sexuales.

\section{Derecho penal anglosajón}

En términos generales se puede afirmar que en los sistemas penales anglosajones o de Common Law se reproducen de manera casi idéntica los problemas derivados de las diversas edades de validez del consentimiento de menores de edad según los ámbitos y, en especial, del consentimiento sexual ${ }^{9}$. Sin embargo, las diferencias en el tratamiento y las instituciones penales son notables por varias razones.

En primer lugar, por el hecho de que en algunos sistemas la competencia para regular la materia no pertenece a un único órgano, sino que es materia compartida entre la Administración federal y estatal o territorios federales. En segundo lugar, por el hecho derivado de lo anterior, de que mientras que la mayoría de edad (incluida la penal) en casi todos ellos se sitúa en los 18 años, la edad de consentimiento sexual fuera del matrimonio oscila entre los 16 y los 18 años y es fijada por el legislador estatal. Como se verá, en algunas ocasiones y hasta hace poco, se establecían incluso edades distintas atendiendo a la modalidad de relación sexual. En el caso concreto de los Estados Unidos existen diferencias muy notables entre Estados federados en cuanto a la mayoría de edad sexual.

En tercer lugar, por la propia tradición jurídica en el ámbito penal. La figura del statutory rape o violación definida por estatuto o ley, en contraposición a la definida por la jurisprudencia de los Tribunales es una modalidad típica de relaciones sexuales sin violencia ni intimidación y con penetración (sexual intercourse) con una persona a priori incapaz de prestar

9 En el ámbito europeo, las diferentes edades de consentimiento sexual se pueden consultar en la Agencia Europea para la Protección de los Derechos Fundamentales (FRA). Los datos consignados son los referentes a 2017. Su última actualización es de 19/10/2018 y se encuentran disponibles en https://fra.europa.eu/en/publications-and-resources/dataand-maps/minag?mdq1 $=$ dataset 
consentimiento sexual válido. A ello hay que añadir que no se admite como causa de exclusión de la culpabilidad el error sobre la edad de la víctima, salvo excepciones tasadas. La configuración del statutory rape como delito de responsabilidad objetiva en algunos de sus elementos y sus consecuencias (Véase. infra), puede modularse a través de la introducción de la cláusula «diferencia de edad entre la víctima y el acusado o proximidad en edad».

La exención de responsabilidad penal a través de esa cláusula busca flexibilizar los efectos no deseados de la rigidez que provoca la cercanía o el solapamiento de etapas de desarrollo, psicológico, sexual y biológico. Sin embargo, como se verá a continuación, la interpretación de su ámbito de aplicación no es cuestión sencilla. En el Derecho penal anglosajón, la exención de responsabilidad por cercanía en edad ha sido especialmente utilizada para suavizar los efectos de la aplicación del statutory rape a prácticas sexuales consentidas entre menores de edad sexual y menores de edad penal. Por un lado, para hacer frente a los efectos no deseados de una regulación con penas elevadas especialmente cuando existe penetración. En ocasiones esa circunstancia convierte la conducta en violación (rape), sin posibilidad si quiera de reconducirla a través de la modalidad del child molestation. Las consecuencias son especialmente graves cuando los Legisladores penales optan por elevar las edades de consentimiento sexual ${ }^{10}$. Por otro lado, la cercanía en edad se utiliza también para evitar los efectos de las inscripciones en Registros de Delincuentes Sexuales, cuyos antecedentes persisten en el tiempo más allá de la propia cancelación del antecedente penal (Véase. Infra) ${ }^{11}$.

\subsection{La responsabilidad objetiva o strict liability y los delitos sexuales}

Los llamados delitos de responsabilidad objetiva o strict liability offenses son una modalidad de ilícitos penales que permiten afirmar la

10 Sobre la evolución histórica en la edad de consentimiento sexual, véase BuLlough, V. L., "Age of consent. A historical overview», en Bullough, V. L. / GraupNer, H., (2006), Adolesence, sexuality and Criminal Law. Multidisciplinary perspectives, First Edition, Taylor Francis Group, New York, pp. 25-42.

11 Con respecto a esta consecuencia en nuestro Ordenamiento jurídico, véase la Sentencia 37/2018, del Juzgado Contencioso-Administrativo $n^{\circ} 3$ de Zaragoza, de 19 de febrero de 2018 y el comentario a la misma de MARco FrAncia, M. P., «La inscripción en el Registro de Delincuentes Sexuales, una pena de inhabilitación especial contraria al principio de legalidad. A propósito de la Sentencia núm. 37/2018 del Juzgado de lo Contencioso-Administrativo núm. 3 de Zaragoza», La Ley, no 9256, 2018, pp.7-8. También, Martínez Guerra, A., "Notas sobre el Registro de delincuentes Sexuales», Revista de Actualidad Criminológica, núm. 4, 2016, pp. 47-48 y Molina Blázouez, C, «A propósito de la constitucionalidad del Real Decreto 110/2015, que regula el registro de delincuentes sexuales», La Ley Penal: Revista de Derecho Penal, Procesal y Penitenciario, vol. 119, 2016, pp. 1-15. 
comisión del delito aunque alguno o algunos de sus elementos no sean abarcados por el dolo del autor. En el caso concreto de la modalidad de statutory rape británico que castiga mantener relaciones sexuales con un menor de 13 años, no se exige para la realización del tipo que el dolo del autor abarque la edad de la víctima ${ }^{12}$. La simple concurrencia del dolo genérico sirve para considerar realizado el tipo (Véase infra. 2.2).

Según la doctrina, el origen de los delitos de responsabilidad objetiva diverge en el Reino Unidos y en los Estados Unidos de América. En el primero, autores como SAYRE lo sitúan a mediados del S.XIX y en casos de difamación o libelo cometidos a través de prensa escrita ${ }^{13}$. A partir de ahí, según el autor se extendieron fundamentalmente a los ámbitos relativos a la salud pública. En el caso de Estados Unidos, CHRISTOPHER \& CHRISTOPHER señalan la gran influencia del fallo Regina $v$. Prince (1875) durante casi cien años ${ }^{14}$. En aquella decisión se condenó a un varón por haber sustraído a una mujer soltera menor de 16 años de la posesión del padre. El acusado creyó de buena fe que la víctima era mayor de esa edad. Sin embargo, el Tribunal entendió que la finalidad de la norma, la Offenses against the person Act de $1861^{15}$, no podía hacer depender la comisión del delito del conocimiento que el autor tuviera de la edad de la víctima. Lo que se perseguía con ella era que el varón que tuviera relaciones sexuales consentidas fuera del matrimonio con mujeres jóvenes, asumiera el riesgo en caso de que éstas no alcanzaran la edad de consentimiento sexual ${ }^{16}$. El fallo recogía también el voto particular del Juez Brett, quien contrariamente consideraba que en Inglaterra no podía condenarse por la comisión de un delito en ausencia de parte del elemento subjetivo o mens rea ${ }^{17}$.

Por su parte, CARPENTER sitúa la construcción doctrinal de las strict liability offenses en los riesgos derivados de la revolución industrial y

12 UK Public General Acts, c. 42, Sexual Offenses Act 2003, secs. 5-9. Véase infra las observaciones realizadas en el apartado 4. Reino Unido e Irlanda del Norte y República de Irlanda.

13 SAYre, F. B., «Public Welfare Offenses», Columbia Law Review, vol. 33, 1933, pp. 57-58, notas 7 y 8, para quien, el Act of the Parliament de 1836 supuso la utilización de la strict liability en los casos de difamación o libelo periodístico.

14 Christopher, R.L. / Christopher, K.H., "The paradox of statutory rape», Indiana Law Review, vol. 87, 2012, p. 517, nota al pie 95.

15 Regina v. Prince, LRR2, CCR 154 (1875), 50, 51, en aplicación de la sec. 55 (abduction of a girl under the sixteen years of age) de la Offense against the person Act, 1861 , c. 100,6 th august.

16 Acerca de los diferentes modelos y teorías sobre distribución y desplazamiento del riesgo, véase Moore, M.M., Causation and responsibility: an Essay in Law, Morals, and the Metaphysics, Oxford University Press, Oxford, 2014. Con respecto al fallo Regina v. Prince (1875), cfr. EL MISMO, pp 204-205. Sobre el símil de asunción de riesgos con la celebración de contratos con menores de edad, Véase, Guerrina, B., "Mitigating Punishment for Statutory Rape», University of Chicago Law Review, 1998, vol. 65-4, pp. 1262-1263.

17 Regina v. Prince, LRR2, CCR 154 (1875) (Judge Brett). 
sobre todo, en la necesidad de incrementar los niveles de protección y los controles en determinadas industrias ${ }^{18}$. Por ello, junto a los tradicionales delitos malum in se, aparece esta nueva categoría que se distingue fundamentalmente porque, en primer lugar, el riesgo de realización de la conducta lo asume íntegramente el autor al no exigir prueba del conocimiento de alguno de los elementos del tipo (edad de la víctima). En segundo lugar, porque su finalidad es la de proteger el interés público (public welfare offense). En tercer lugar, porque las penas asociadas a este tipo de infracciones penales son relativamente bajas y, finalmente, por la insignificancia del estigma que llevan asociadas estas conductas ${ }^{19}$. La concurrencia de estos cuatro elementos es lo que, a juicio de la doctrina mayoritaria, podría en su caso justificar la existencia de esta modalidad de delitos. Sin embargo, en opinión de CARPENTER la inclusión del statutory rape en esta categoría no se ajustaría a estos principios porque las penas son elevadas y la estigmatización es grave, entre otras razones por obligatoria inscripción de las personas condenadas en Registros de Delincuentes Sexuales ${ }^{20}$. En el mismo sentido se pronuncia WASSERSTROM, para quien la existencia de delitos de responsabilidad objetiva en materia sexual no se corresponde con función social alguna de la norma ${ }^{21}$.

Para hacer frente a las consecuencias derivadas del statutory rape entre los delitos de responsabilidad objetiva nace lo que CARPENTER denomina el modelo híbrido, que viene a completar al modelo tradicional de malum in se y strict liability ${ }^{22}$. El elemento esencial de ese modelo es precisamente la toma en consideración de la diferencia de edad entre autor y la víctima del delito, con una formulación muy similar a la redacción del nuevo art. 183 quáter CP. No obstante, su redacción y sus efectos de exclusión de antijuridicidad de la conducta, están pensados para aplicarse a situaciones de relaciones sexuales entre menores de edad sexual y menores de edad legal a quienes se aplicaría el Derecho penal de menores. Ésa es la razón por la que la cláusula es también conocida como «cláusula Romeo y Julieta»23.

18 CARPENTER, C.L., «On statutory rape, strict liability and the public welfare offense model», American University Law Review, vol. 53, 2003-2004, pp. 323-324.

19 SAYre, F, B., "Public Welfare Offenses», ob, cit, p. 56, mantiene la necesidad de que sean penas de multa. Sobre la distribución del riesgo como forma de imputación y su relación con las teorías de la pena, véase en castellano VARELA, L., "Strict liability como forma de imputación jurídico penal», Indret, 3, pp. 1-26.

20 CARPENTER, C.L., "On statutory rape, strict liability and the public welfare offense model», ob, cit, pp. 317-318.

21 WASSERStRom, R.A., "Strict liability in the Criminal Law», Stanford Law Review, vol. 12, 1959-1960, p. 745.

22 CARPENTER, C.L., "On statutory rape, strict liability and the public welfare offense model», ob, cit, pp. 323-324.

23 La problemática de la aplicación a relaciones sexuales y otro tipo de comportamientos sexuales entre menores también fue planteada por la Fiscalía General del Estado en sus Circulares 2/2015 de 19 de junio, sobre delitos de pornografía infantil tras la reforma operada por la LO 1/2015 y 1/2017, de 6 de junio, sobre la interpretación del 
En los últimos tiempos, la preocupación por los efectos de la sanción penal asociada a este tipo de comportamientos unida a la elevación de la edad de consentimiento sexual en términos generales, ha llevado a algunos legisladores a contemplar el error del sujeto activo acerca de la edad de víctima como elemento para reducir la pena asociada al comportamiento. Como se verá a continuación, si bien ese error se admite dentro de unas franjas de edad y no excluye por completo la responsabilidad penal del sujeto, permite reducir la pena al rebajar la categoría del ilícito penal (felony) a delito leve (misdemeanor), evitando con ello la correspondiente inscripción en el Registro de Delincuentes Sexuales.

\subsection{El statutory rape o violación definida por estatuto o ley. Evolución y críticas}

La figura del statutory rape (o delito de violación definido por estatuto) sigue siendo una figura polémica. Si bien la existencia de delitos de responsabilidad objetiva está perfectamente asumida en los sistemas anglosajones, la evolución de los tipos penales, especialmente la elevación de la edad de consentimiento sexual del menor de edad, provoca consecuencias importantes por los cambios sociales y la extensión de la protección del menor de edad. Esta última se corresponde con un fenómeno reciente en sociedades desarrolladas, especialmente en el ámbito de las clases sociales medidas durante el s. Xx, que autores como wEEKs han venido calificando como una intensa inversión emocional en el niño y el correspondiente miedo a su corrupción sexual ${ }^{24}$.

En opinión de GUERRINA, la propia evolución histórica del statutory rape sirve para mantener y defender muchas y variadas posturas acerca del bien jurídico protegido por el tipo penal. Si en un primer momento el statutory rape servía para proteger y garantizar la virginidad de la mujer soltera y, por tanto, la moral y la decencia, la propia evolución ha permitido sostener otras posturas como la necesidad de proteger a la mujer joven

art. 183 quáter del Código Penal. En ambas, la FGE apostó por un análisis individualizado de los casos, que permita solicitar el archivo de las actuaciones cuando se estime que no se colma el mínimo de antijuridicidad material (art. 637 LECRIM). Un criterio similar ha sostenido recientemente el propio Comité de Lanzarote en su Opinión de junio de 2019. Véase, council of europe, Lanzarote Committee, Committee of the Parties to the Council of Europe Convention on the protection of children against sexual exploitation and sexual abuse, Opinion of the Lanzarote Committee on child sexually suggestive or explicit images and/or videos generated, shared and received by children, 6 June 2019, texto disponible en https://search.coe.int/directorate_of_communications/Pages/result_details. aspx? ObjectId $=0900001680956 \mathrm{a} 88$

24 Weeks, J., Sex, Politics and Society: the regulation of sexuality since 1800, $3^{\text {rd }}$ Edition, Routledge, New York, 2012, p. 60. 
frente a los riesgos de los embarazos no deseados, la protección de daño a su indemnidad sexual ${ }^{25} \mathrm{y}$, finalmente, la propia explotación sexual ${ }^{26}$.

En la evolución de la teoría del bien jurídico protegido por el statutory rape confluyen posiciones enfrentadas que se han agudizado cuando además la formulación del tipo penal se realizaba en términos de género no neutrales (non-gender neutral) ${ }^{27}$, es decir, sujeto pasivo mujer y sujeto activo varón. La primera de ellas, la vulneración del principio de igualdad de protección ante la ley. La segunda, las críticas desde sectores feministas que entendían que la figura del statutory rape era una manifestación más de un sistema patriarcal que negaba la validez del consentimiento sexual de mujeres jóvenes.

Con respecto a la primera de las cuestiones, el Tribunal Supremo de los Estados Unidos en su decisión Michael M. v. Superior Court of Sonama (1981) ${ }^{28}$, mantuvo que la entonces redacción de la Sección 261.5 del Código Penal de California no suponía una vulneración de la Enmienda Décimocuarta de la Constitución Norteamericana (Equal Protection) al castigar al varón que tuviera relaciones sexuales con una mujer que, sin ser su esposa, no hubiera alcanzado la edad de 18 años ${ }^{29}$.

La redacción del Código penal de California definía el statutory rape como "an act of sexual intercourse accomplished with a female not the wife of the perpetrator, where the female is under the age of 18 years ${ }^{30}$.

25 Con respecto a la evaluación del daño, véase RIND, B., «An Empirical examination of Sexual Relations Between Adolescents and Adults; They differ from those between children and adults and should be treated separately», en Bullough, V.l. / Graupner, H., Adolescence, sexuality and Criminal Law. Multidisciplinary perspectives, ob, cit, pp. 55-62.

26 GuerrinA, B., «Mitigating Punishment for Statutory Rape», ob, cit, pp. 1259 y ss. Entre los ámbitos de protección señalados por la autora destaca la salvaguarda y prevención de la moral en las épocas de las grandes migraciones de los núcleos rurales a los urbanos, situaciones en las que las mujeres jóvenes de clase trabajadora salían del ámbito de protección y vigilancia de su propia familia.

27 Con respecto a la problemática en el ámbito de las relaciones homosexuales, véase GraupNer, H., "Love versus abuse: Crossgenerational sexual relations of minors: a gay rights issue?», Journal of Homosexuality, vol. 37-4, 1999, pp. 23-56.

28 MichaEL M. V. Superior Court of Sonama 450 US 464 (1981), 23 March. Decisión adoptada por 5-4, con los votos a favor de los Jueces Rehnquist, Burger, Stewart, Powell y Blackmun (voto concurrente) y en contra de los Jueces Brennan (con voto concurrente de White y Marsall) y Marsall.

${ }_{29}$ El demandante ante el Tribunal Supremo había sido condenado por sentencia del Tribunal de instancia en una decisión aprobada con 4 votos a favor y 3 en contra. La sentencia fue confirmada a su vez por el Tribunal de Apelación de California. En el momento de los hechos, el demandante tenía 17 años y medio y la víctima 16 años y medio. Cfr. Michael M. v. Superior Court of Sonoma County, 25 Cal. 3d 608, 601 P.2d 572, $159 \mathrm{Cal}$. Sobre los detalles del fallo, véase LAURER, R.J., «Fourteenth Amendment- Statutory rape: protection of minor female and prosecution of minor male», The Journal of Criminal Law and Criminology, vol. 72, 1981, pp. 1374-1377.

30 \& 261.5 Cal. Penal Code Ann. (West Supp. 1981). La redacción actual del precepto utiliza los términos person, spouse y perpetrator, sin aludir al sexo de ninguno de los dos. 
En su razonamiento, el Tribunal Supremo entendía que dicha sección del Código Penal de California trataba de proteger a las mujeres jóvenes de consecuencias perjudiciales como embarazos adolescentes. Por ello criminalizaba la conducta de los varones que mantuvieran relaciones sexuales con mujeres que no hubieran alcanzado la edad de consentimiento sexual, siempre que no existiera vínculo matrimonial ${ }^{31}$. Las mujeres, entendía el Tribunal, sufrían de manera desproporcionada las consecuencias y ello legitimaba constitucionalmente al Estado de California para sancionar este tipo de conductas a través del statutory rape por dos razones. La primera, porque hombre y mujer, entendía el Tribunal Supremo, no se encontraban en la misma situación frente a los problemas y riesgos derivados de las relaciones sexuales: «el riesgo de un embarazo no deseado constituye per se una importante medida disuasoria en la mujer, pero no en el hombre». La segunda, derivada de la anterior, porque existía un interés público en la prevención de los «embarazos ilegítimos» (pregnancy prevention rationale) debido a la alta tasa de aborto de adolescentes y a elevada la probabilidad de que muchos de esos menores fueran entregados en custodia a instituciones públicas al nacer, incrementando el gasto de las partidas sociales ${ }^{32}$.

La figura del statutory rape empieza a despertar fuertes críticas en diversos sectores a finales de los años 70 en los Estados Unidos y en el Reino Unido. En 1984 olsEN identificó dos elementos que explicaban la postura del movimiento feminista en torno del statutory rape. La primera, la naturaleza sexista del control social y la asunción de que, en la práctica, control social significaba control de la mujer. La segunda, la naturaleza sexista de la libertad sexual y, por lo tanto, la identificación de la libertad con la libertad de los hombres para explotar a las mujeres ${ }^{33}$. Desde otro sector del movimiento feminista se señalaba también el acusado carácter paternalista del statutory rape al presumir la incapacidad de la mujer joven para prestar un consentimiento sexual válido $\mathrm{y}$, por tanto, la

31 Michael M. v. Superior Court of Sonama 450 US 464 (1981), 23 March, footnote 5: "This is because teenagers are disproportionately likely to seek abortions. Center for Disease Control, Abortion Surveillance 1976, pp. 22-24 (1978). In 1978, for example, teenagers in California had approximately 54,000 abortions and 53,800 live births. California Center for Health Statistics, Reproductive Health Status of California Teenage Women 1, 23 (Mar.1980)».

32 Michael M. v. Superior Court of Sonama 450 US 464 (1981), 23 March, footnote 6: "The policy and intent of the California Legislature evinced in other legislation buttresses our view that the prevention of teenage pregnancy is a purpose of the statute. The preamble to the Pregnancy Freedom of Choice Act, for example, states: "The legislature finds that pregnancy among unmarried persons under 21 years of age constitutes an increasing social problem in the State of California». Sobre el incremento de los costes económicos, sociales e incluso penintenciarios, véase MAYNARD, R.A. (ed.), Kids having kids, The economic costs and social consequences of teen pregnancy, Routledge, New York, 1997.

33 OlsEN, F., "Statutory rape: a feminist critique of the rights analysis», Texas Law Review, vol. 63, 1984, p. 370. 
necesidad de ser protegida de sí misma ${ }^{34}$. Esta postura inevitablemente retrotraía a la justificación social del statutory rape a finales del s. XIX y principios del XX.

El mantenimiento de la figura del statutory rape en los textos penales ha obligado a articular soluciones controvertidas cuando las conductas se dan entre sujetos que no son excesivamente próximos en edad. En estos casos, los Tribunales han aceptado como causas de exclusión de la responsabilidad penal el comportamiento de la víctima, la existencia de posibles relaciones sexuales previas (experiencia sexual de la mujer) e incluso aspectos relativos a la iniciativa en el primer contacto sexual. Para algunas corrientes feministas ello es consecuencia del puritanismo social de principios del s. Xx que, al elevar la edad de consentimiento sexual de manera ilógica, acaba obligando a buscar soluciones que mitiguen los efectos desproporcionados de las penas asociadas a estos delitos ${ }^{35}$. La aceptación de esos elementos en valoración para determinar la posible exclusión de la responsabilidad corre el riesgo de extenderse a otros supuestos, cuyo elemento de discusión no es la validez del consentimiento de la víctima menor de edad, sino la existencia o no de consentimiento en situaciones de posible intimidación ambiental o similares.

Desde los ámbitos médicos y socio sanitarios, la justificación de la figura del statutory rape en los códigos penales también encuentra sus detractores. Más allá de los problemas que se pueden suscitar con la intervención en la sexualidad de los púberes adultos e incluso adolescentes a través del Derecho penal ${ }^{36}$, estudios médicos, psicológicos y sociológicos ponen de manifiesto la problemática para identificar y separar situaciones consentidas de situaciones de abuso. Ello se debe a las percepciones sobre valor de la conducta de la partes ${ }^{37}$ tanto en relaciones de naturaleza heterosexual como homosexual ${ }^{38}$, al papel del personal médico en su

34 GuerrinA, B., «Mitigating Punishment for Statutory Rape», ob, cit, p. 1261.

35 Ibidem, pp. 1253-1254, que mantiene, como otros autores, que el statutory rape tiene sentido cuando la edad de consentimiento sexual es baja y se sitúa en torno a los 12 años.

36 Graupner, H., «Love versus abuse: Crossgenerational sexual relations of minors: a gay rights issue?», ob, cit, pp. 23-56, donde se expone la problemática de la edad de consentimiento sexual y el conflicto con el núcleo de derechos fundamentales desde la óptica de la protección reconocida por el TEDH (art. 8.1 CEDH). EL MISMO en «Sexual consent: The Criminal Law in Europe and Overseas», Archives for Sexual Behaviour, vol. 29-5, 2000, pp. 416, nota al pie 4.

37 OudERKEK, B. A. / FARR, R. H. / Reppucci, N. D., «Defining sexual abuse victimization and revictimization. Is love or sexual abuse? Young adults'perceptions of statutory rape», Journal of Child Abuse, vol. 22, 2013, pp. 858-877.

38 Rind, B., «An Empirical Examination of Sexual Relations Between Adolescents and Adults: They Differ from Those Between Children and Adults and Should Be Treated Separately», en Bullough, V. L. / Graupner, H., Adolesence, sexuality and Criminal Law. Multidisciplinary perspectives, ob, cit, pp. 57-60. 
denuncia $^{39}$, a la dificultad para valorar el posible daño o lesión al bien jurídico protegido y su repercusión a futuro en la sexualidad de la vícti$\mathrm{ma}^{40} \mathrm{y}$, finalmente, el impacto sobre la mujer de embarazos adolescentes en relación con el papel asumido por los padres ${ }^{41}$.

\section{Estados Unidos de América}

Los Estados Unidos de América es uno de los países que más diferencias presenta en la regulación del consentimiento sexual, como consecuencia de su propia estructura de Estado Federal. En primer lugar, porque la mayoría de edad tienen una doble regulación, ya que la fijada en la Constitución (18 años) se refiere a la edad en la que se adquiere el derecho al voto ${ }^{42}$. A excepción de 3 Estados federados, en 47 de ellos, incluido el Distrito de Columbia, la mayoría de edad se adquiere a los 18 años (Vid infra) En segundo lugar, porque el Derecho de Familia, disciplina en la que se contienen entre otros todos los aspectos relativos a la capacidad para contraer matrimonio, es competencia exclusiva de los Estados federados. Ello incluye el establecimiento de la edad legal para poder celebrar nupcias y las dispensas previstas cuando los sujetos no alcanzan la edad legal para ello. Esas circunstancias condicionan el hecho de que, por ejemplo, los Estados Unidos de América no hayan ratificado la Convención de Derechos del Niño de la ONU de $1989^{43}$, aunque ello no signifique que los Tribunales norteamericanos rechacen siempre los estándares internacionales en materia de protección o de intereses del menor ${ }^{44}$.

39 Finder, S. / Korenman S., «Community, context, and the contrasting roles of clinicians and researchers: challenges raised by statutory rape», American Journal of Bioethics, vol. 14-10, 2010, pp. 55-57.

40 Carpenter, B. / O’Brien, E. / Hayes, S. / Death, J., «Harm, responsibilty, age and consent», New Criminal Law Review, vol, 17-1, 2014, pp. 42 y ss.

41 Bunting, L. / Mcauley, C., «Teenage pregnancy and parenthood: the role of the fathers", Child \& Family Social Work, vol. 3-9, 2004, pp. 295-303, en el que se exponen resultados de estudios llevados a cabo en Estados Unidos y Reino Unido.

42 Constitución de los Estados Unidos de América, 1787. Enmienda XXVII. Ratificada el 1 de julio de 1971. "Sección Primera. El derecho a votar de los ciudadanos de los Estados Unidos, de dieciocho años de edad o más, no será negado o menguado por los Estados Unidos ni por ningún otro estado por razón de edad».

43 Convención sobre los Derechos del Niño adoptada y abierta a la firma y ratificación por la Asamblea General en su Resolución 44/25, de 20 de noviembre de 1989, entrada en vigor 2 de septiembre de 1990. Convención firmada por los Estados Unidos 15 de febrero de 1995 (UNTS, vol. 1577, p. 3). Sobre el conflicto en materia de Derecho de Familia, véase Dehart, G. F., "Comity, Conventions, and the Constitution: State and Federal Initiatives in International Support Enforcement», Family Law Quarterly, vol. 28-1, 1994, pp. 89-115 y LEE, S., "Child's voice vs. parent's control: resolving the tensión between the Convention on the rights of the child and U.S Law», Columbia Law Review, vol. 117-3, 2017, pp. 687-728.

44 Véanse las observaciones de PEARLSTEIN, L., "Walking the tightrope of statutory rape law: using International legal standars to serve the best interest of juveline offenders 
A pesar de que la Familia como tal no tiene reconocimiento constitucional expreso, el Tribunal Supremo de los Estados Unidos ha desarrollado toda una extensa línea jurisprudencial que ubica la institución familiar dentro del derecho fundamental a la privacidad y libertad (Décimo Cuarta Enmienda). Por ello, como sostiene GUgGENHEIM «el Tribunal Supremo ha establecido que el derecho a la integridad familiar existe, pese a la ausencia de referencias específicas en la Constitución " ${ }^{45}$. Con el paso del tiempo, el ámbito de esos derechos familiares y por tanto, la protección frente a la intromisión de los poderes públicos, se ha ido extendiendo de manera significativa a los derechos y obligaciones parentales, al derecho a la educación de los padres, a los propios derechos de los hijos e incluso al uso de métodos anticonceptivos en fallos como Griswold v. Connecticut $(1965)^{46}$. En esa histórica decisión, la Corte Suprema entendió que la tipificación del asesoramiento médico y la dispensa de métodos anticonceptivos a los matrimonios heterosexuales contenida en el los §§ 53-32 y 54-196 del General Statutes of Connecticut (1958 rev. $)^{47}$ atentaba contra la necesaria «intimidad que debe existir entre marido y mujer y aceptada en la creación de la propia institución del matrimonio que no sólo debe permitir, sino que en cualquier edad tiene que fomentar y proteger. Una cosa es que el Estado utilice su poder para prohibir las relaciones sexuales extramaritales en su conjunto, o establecer quién puede contraer matrimonio, y otra muy diferente, cuando habiendo reconocido la existencia de un matrimonio y sus intimidades inherentes, utiliza el derecho penal para regular detalles de esa intimidad» ${ }^{48}$.

En tercer lugar, porque los Estados federados tienen también la competencia para establecer los requisitos (entre ellos la edad de la gestante) para la interrupción voluntaria del embarazo dentro de los límites constitucionales marcados por el Tribunal Supremo de los Estados Unidos en

and victims", American Criminal Law Review, vol. 47, 2010, pp. 117-118. Especialmente interesante, las referencias realizadas en la nota pie 60, en el asunto Batista v. Batista, Conn, Super. Court, June 18, 1992, sobre las referencias a la Convención de Derecho del Niño de 1989 al ser España parte del mismo.

45 Guggenheim M., "Family Law», en Fundamentals of American Law, Oxford University Press, New York, 1998, p. 400. Sobre los orígenes religiosos y sociales de la regulación de la institución familiar en los Estados Unidos de América, Hamilton, V., «Principles of Family Law», Fordham Law Review, vol. 75-1, 2006, pp. 35 y ss.

46 Sobre evolución de la protección constitucional en diversas esferas en el Derecho de Familia en los Estados Unidos, véase por todos, MiNow, M., «We, the Family: Constitutional Rights and American Families», The Journal of American History, The Constitution and American Life: A Special Issue, vol. 74-3, 1987, Dec., pp. 959-983.

47 General Statutes of Connecticut (1958 rev.) \$\$ 53-32. "Any person who uses any drug, medicinal article or instrument for the purpose of preventing conception shall be fined not less than fifty dollars or imprisoned not less than sixty days nor more than one year or be both fined and imprisoned"y General Statutes of Connecticut (1958 rev.) \$§ 54-196: "Any person who assists, abets, counsels, causes, hires or commands another to commit any offense may be prosecuted and punished as if he were the principal offender".

48 Griswold v. Connecticut 381 U.S 479 (1965). 
Roe v. Wade $(1973)^{49}$. En esa histórica decisión tomada por 7 votos a favor y 2 en contra, el Alto Tribunal entendió que los preceptos del Código Penal de Texas que tipificaban el aborto salvo en los casos de riesgo para la vida de madre ${ }^{50}$ vulneraban el derecho a la privacidad e intimidad contenido en la Enmienda Decimocuarta de la Constitución. El Tribunal Supremo venía a reinterpretar el contenido un derecho fundamental incorporado a la Constitución en 1868, creando lo que REGAN denominó «derecho constitucional al aborto» ${ }^{51}$. Desde entonces, fallos como Planned Parenthood v. Casey (1992) ${ }^{52}$ y Whole Women's Health v. Hellerstedt $(2016)^{53}$ han afianzado la protección constitucional de la interrupción del embarazo, prohibiendo restricciones de acceso o ejercicio del mismo introducidas por algunos Estados. Actualmente, el Tribunal Supremo de los Estados Unidos está pendiente de pronunciarse en el asunto June Medical Services LLC v. Gee sobre las restricciones introducidas por el Estado de Louisiana en su reforma de $2014^{54}$. El contenido de la norma, basada en la aprobada en Texas en $2011^{55}$ y declarada inconstitucional en Whole Women's Health v. Hellerstedt (2016), establece la obligación de las mujeres de contar con asistencia garantizada en servicios de obstetricia y ginecología en hospitales situados a una distancia máxima de 30 millas de aquél en el que se produce la interrupción del embarazo. Restricciones similares se han introducido también en Estados como Georgia, Kentucky, Missouri, Arkansas y Tennessee, modificando el límite gestacional de 24 semanas establecido en Roe v. Wade (1973). Por lo que se refiere a la edad de la gestante para la interrupción del embarazo, la competencia es igualmente del Estado federado, que puede exigir notificación y/o consentimiento de uno de los progenitores o de ambos. Este aspecto es especialmente importante cuando nos encontramos ante relaciones sexuales de una menor de edad sexual con vínculo matrimonial o sin él ${ }^{56}$.

En cuarto lugar, porque la regulación de los delitos contra libertad sexual son también competencia estatal, de ahí que la redacción de los Códigos penales de los Estados federados refleje la tradición y la importancia que el Estado en concreto le atribuye a la materia ${ }^{57}$. Sin embargo, los condicionantes descritos anteriormente no han impedido el desarro-

49 Roe v. Wade 410. U.S 113 (1973), 22 January, 1973, con respecto a las restricciones aprobadas por el Estado de Texas.

50 Texas Rev. Crim. Stat. (1911), arts. 1191-194 y 1196.

51 Regan, D.H., "Rewriting Doe v. Wade», Michigan Law Review, vol. 77, 1979, p. 1569.

52 Planned Parenthood v. Casey 505, US (1992).

53 Whole Women's Health v. Hellerstedt 579 US (2016).

54 Louisiana Law, Act 620, 2014.

55 Texas House Bill 2 (H. B. 2), 11 June 2013.

56 Véase Planned Parenthoof v. Casey 505 US 833 (1998) con respecto a las obligaciones de notificación de la Pennsylvania Abortion Control Act de 1982.

57 Sobre la evolución de la edad de consentimiento sexual, véase Fischel J.J., «Per se or Power?, Age and sexual consent», Yale Journal of Law and Feminism, vol. 22-2, 2010, pp. 286 y ss. 
llo de instituciones muy similares o de elementos comunes en materia del consentimiento de los menores de edad y de la figura de statutory rape. En gran medida esto ha sido posible a la influencia del Model Penal Code (MPC) de 1962 en la concreta regulación de los códigos penales de los Estados federados ${ }^{58}$.

Finalmente, porque la edad de responsabilidad penal del menor es también competencia de los Estados federados, excepto para los delitos federales ${ }^{59}$. Con respecto a esta materia, se da también la circunstancia de que la regulación norteamericana no establece una edad a partir de la cual es exigible esa responsabilidad, sino que configura la minoría de edad como una causa de exclusión de la responsabilidad (infancy defense) que permite enjuiciar el hecho a través de un sistema penal de menores (juvenile courts) $^{60}$. El sistema norteamericano no tiene una edad mínima de responsabilidad penal del menor y el interés se desplaza a dilucidar si un menor de edad penal puede ser juzgado como tal o, por el contrario, debe ser «transferido» (waiver laws) a la jurisdicción penal de adultos ${ }^{61}$. En esa decisión el sistema toma como elemento objetivo la gravedad del delito cometido por el menor. En definitiva, lo que se hace es determinar los 18 años como edad hasta la que el menor puede ser enjuiciado como tal, con algunas excepciones entre los 18 y los 21 años. Este tratamiento de la responsabilidad penal de la minoría de edad condiciona a su vez la responsabilidad de los menores en materia de delitos sexuales.

\subsection{Regulación Estatal}

Para el estudio de la regulación estatal de los delitos sexuales en su modalidad de statutory rape o violación definida por estatuto, es nece-

58 Sobre la influencia de la regulación del MPC en delitos sexuales y su relevancia, véase con carácter general, FLETCHER, G.P., «Dogmas of the Model Penal Code», Buffalo Law Review, vol. 2-3, 1998-1999, pp. 3-24. Específicamente sobre los delitos sexuales, Denno, D. W, «Why the Model Penal Code's Sexual Offense Provisions should be pulled and replaced», Ohio State Journal of Criminal Law, vol. 1-1, Fall, 2003, pp. 208-210.

5918 U.S. Code \$ 5031. Definitions. En este precepto, se define «menor» como toda persona que no ha alcanzado la edad de 18 años. En el ámbito exclusivamente federal, véase DOYLE, C., Juvenile Delinquents and Federal Criminal Law: The Federal Juvenile Delinquency Act and Related Matters, Congressional Research Service, 6 Nov. 2018, pp. 1-23, disponible en https://fas.org/sgp/crs/misc/RL30822.pdf

60 Sobre la tradición y evolución de la institución de la infancy defense en el sistema anglosajón, véase WaLkover, A., "The Infancy Defense in the New Juvenile Court», University of California Law Review, vol. 31, 1984, p. 509.

61 Sobre el procedimiento y las posibilidades, véase Heilbrun, K. / De Matteo, D. / King, C. / Filone, S., Evaluating Juvenile Transfer and Disposition: Law, Science, and Practice, Routledge Taylor and Francis Group, New York and London, 2017, pp. 3768. Véase también OAS/Serv. L/V/II Doc. 34/18 InTER-American Commission Of Human RIGHTS, The situation of Children in the Adult Criminal Justice system in the United States, Washington D.C, 1 Mar. 2018, pp. 37 y ss. 
sario tener presente los cinco ámbitos en los que la edad juega un papel determinante.

El primero de ellos la mayoría de edad, establecida en los 18 años en 47 Estados y el Distrito de Columbia. Excepcionalmente, los Estados de Nebraska y Alabama la sitúan en los 19 años $^{62}$ y Mississippi en $21^{63}$. En segundo lugar, la mayoría de edad para contraer matrimonio, establecida también por la propia ley estatal, que varía de manera significativa de un Estado federado a otro. De la misma forma que ocurre en otros sistemas jurídicos, la mayoría de edad legal puede no coincidir con la establecida para contraer matrimonio, dado que se prevé la posibilidad de dispensa mediante consentimiento parental o judicial. En los Estados Unidos, hay Estados que establecen esa edad en los 17 años si hay consentimiento paterno como Indiana ${ }^{64}$ e incluso otros como Carolina del Sur, que hasta el años 2019 establecía la posibilidad de dispensar fijando edades diferentes para varón y mujer si ésta se encontraba embarazada ${ }^{65}$.

En tercer lugar, la mayoría de edad sexual establecida en los respectivos Códigos penales que determina la posible comisión del statutory rape. Así, la edad legal para prestar consentimiento válido para mantener relaciones sexuales oscila entre los 14 y los 18 años. En este último grupo (18 años) se encuentran los Estados de Arizona, California, Florida, Idaho, Mississippi, Dakota del Norte, Oregón, Tennessee, Virginia y Wisconsin ${ }^{66}$. Los 17 años son la edad de consentimiento sexual válido en los Estados de Illinois, Louisiana, Missouri, Nuevo México, New York y Texas ${ }^{67}$. Los Estados de Colorado y Carolina del Sur establecen la edad de consentimiento sexual en los 15 años $^{68}$, mientras que la edad más temprana (14 años) es la fijada por el Estado de Hawaii ${ }^{69}$. El grue-

62 Alabama Code Title 26. Infants and Incompetens, $\delta$ 26-1-1 y Nebraska Revised Statutes Chapter 43. Infants and Juveniles \$ 43-2101. Persons under nineteen years of age declared minors; marriage, effect;person eighteen years of age or older; rights and responsibility.

63 Mississippi Code Title 1. Laws and Statutes \$ 1-3-27. "Minor» defined.

64 Indiana Family Law 31-11-1-4. Minimum age of marriage. Los menores entre 15 y 17 años pueden obtener dispensa judicial en casos de embarazo o nacimiento de hijo.

65 SC Code, Section 20-1-300, precepto derogado por la Act No. 33 Section. 1 2019, en vigor desde el 13 de mayo de 2019.

66 Ariz. Rev.Stat. Ann.\$13-1405(A)(1989); Cal.Penal Code Ann.\$261.5(a)(West Supp.1998); Fla.Stat. \$794.05(1)(1991); Idaho Code Ann. \$18-6101(1)(Supp.1996); Miss .Code Ann.\$97-3-67(Supp.1993); N.D. Cent. Code Ann, \$12.1-20-05 (Supp.1983); \$14-01 (1997); Ore. Rev. Stat. \$\$163.315(1),163.435(1),163.445(1)(1997); Tenn. Code Ann. \$3913-506(a)(Supp.1996);Va.Code Ann.\$18.2-371(1996); Wis.Stat.\$\$948.01(1),948.09(19931994).

67 Ill.Comp.Stat.,ch.720,\$§5/12-15(b)-(c),5/12-16(d)(West1996);

La.Rev.Stat. Ann.\$14:80(A)(1)(West 1986), as amended by 1995 La. Acts no.241, p.670; Mo.Rev. Stat.\$566.034(1994); N.M.Stat.Ann.\$30-9-1_1(F), as amended by 1995 N.M.Laws ch.159, p.1414;N.Y. Penal Law Ann.\$\$130.05(3)(a),130.20(1),130.25(2)(West 1998); Tex.Penal Code Ann.\$\$22.011(a)(2), (c)(1)(West 1994).

68 Colo.Rev.Stat.\$18-3-403(1)(e)(1997); S.C.Code Ann.\$16-3-655(2)(1985).

69 Haw.Rev.Stat.\$707-730(1)(b)(1993). 
so de los Estados establece como edad de consentimiento válido los 16 años: Alabama, Alaska, Arkansas, Connecticut, Delaware, Distrito de Columbia, Georgia, Indiana, Iowa, Kansas, Kentucky, Maine, Maryland, Massachusetts, Michigan, Minnesota, Montana, Nebraska, Nevada, New Hampshire, New Jersey, North Carolina, Ohio, Oklahoma, Pennsylvania, Rhode Island, South Dakota, Utah, Vermont, Washington, West Virginia, Wyoming ${ }^{70}$. Esto es consecuencia de la adaptación de las legislaciones de los Estados federados a la modificación de la Immigration National Act de 1996 para poder aplicar la expulsión de territorio nacional de residentes legales por la comisión de un delito de abuso sexual de un menor (Véase supra, 3.2 Regulación Federal).

Por lo que respecta a la regulación del statutory rape, el sistema sigue utilizando el elemento de la diferencia de edad entre la víctima y el acusado (age differential between the victim and the defendant) para suavizar los efectos penales de la regulación cuando estamos ante conductas cometidas entre menores de edad sexual y legal ${ }^{71}$ o menores de edad sexual y mayores de edad legal pero muy próximos en edad. En estas situaciones, la diferencia de edad es lo que se conoce como la cláusula $R o-$ meo y Julieta, que sirve para impedir la imposición de la pena o reducir los efectos de la misma. Así ocurre en el Estado de Florida, con edad de consentimiento sexual en los 18 años, donde este tipo de excepciones se aplican por ejemplo a una relación sexual consentida entre una persona de 19 años y otra de 16. La finalidad de la norma no es sólo es reducir la pena a través de la consideración del hecho como un delito menor (misdemeanor), sino también impedir la inscripción del sujeto activo en los

70 Ala. Code \$\$13A-6-62(a)(1),13A6-70(c)(1)(1994); Alaska Stat.\$11.41.436(a)(1) (1996); Ark. Code Ann.§§5-14-106(a), 5-14-1_07(a)(1997); Conn. Gen. Stat. \$53a-71(a)(1) (1995); Del. Code Ann., Tit. 11, \$773(2)(1995); D.C. Code \$\$22-4101(3), 22-4108 (1996); Ga. Code Ann. §16-6-3(a) (1996); 1998 Ind. Acts §8, p.774; Iowa Code \$709.4(2)(1987), as amended by 1994 Iowa Acts p.290; Kan. Stat. Ann. \$21-35(a)(1)(1995); Ky. Rev. Stat. Ann. $\$ \$ 510.020(3)(a), 510.060(1)(b)(L e x i s ~ 1990) ;$ Me. Rev. Stat. Ann., Tit. 17-A, \$254(1)(1983), as amended by 1995 Me. Laws p.123; Md. Ann. Code, Art .27, \$\$464B(a)(4), (5),464C(a)(2), (3)(1996); Mass. Gen. Laws, ch.265,\$23 (1992); Mich. Comp. Laws \$750.520d(1)(a)(1991), as amended by 1996 Mich. Pub. Acts p.393; Minn. Stat. \$609.344.1(b)(1996); Mont. Code Ann.\$\$45-5-501(1)(b)(iii),45-5-503(3)(a)(1995); Neb. Rev. Stat. \$28-319(1)(1994 Cum. Supp.); Nev. Rev. Stat. \$\$200.364(3), 200.368 (1997); N.H. Rev. Stat. Ann. \$632-A:3(II) (1986); N.J. Stat. Ann. §2C:14-2(c)(5)(West 1995); N.C.Gen. Stat. Ann. \$14-27.7A(1998 Cum. Supp.); Ohio Rev. Code Ann. \$2907.04(A)(Lexis 1996); Okla. Stat., Tit. 21, \$1111(A)(1) (1983), as amended by 1995 Okla. Sess. Laws ch. 22, §1, p.119; 18 Pa. Cons. Stat. \$3122.1, added by 1995 Pa. Laws 985, \$5 p.987; R.I. Gen. Laws \$11-37-6(1994); S.D. Codified Laws \$22-22-1(5)(1998); 1983 Utah Laws ch. 88, \$16; Vt. Stat. Ann., Tit. 13, \$3252(a)(3)(1998); Wash. Rev. Code \$9A.44.079(1994); W. Va. Code Ann. \$\$61-8B2(c)(1), 61-8B-5(a)(2) (Lexis 1997); Wyo. Stat. Ann. \$6-2-304(a)(i)(1997).

71 Véase al respecto Humphrey v. Wilson, 652 S.E.2d 501, 26 october 2007, declarando inconstitucional la pena asociada para este delito en menores de edad en el Estado de Georgia. 
Registros de Delincuentes Sexuales ${ }^{72}$, cuyo carácter punitivo empieza a ser cuestionado por los propios Tribunales ${ }^{73}$.

Sin embargo, la diferencia de edad entre los sujetos puede producir el efecto contrario cuanto estemos ante víctima sin edad legal y exista una diferencia de edad sustancial con el acusado. Así, por ejemplo, el Estado de Florida castiga como delito (felony) los comportamientos sexuales entre una persona de 24 años o mayor y otra de 16 ó 17 años. En este caso además, el comportamiento previo de la víctima resulta irrelevante a efectos de valorar la posible persecución del delito ${ }^{74}$.

\subsection{Regulación Federal}

La regulación federal de los delitos sexuales se encuentra contenida en el Título 18 del US Code, Parte I, capítulos 109A, 109B y 11075. Estos tipos penales se aplican, de acuerdo con el sistema federal, cuando los delitos se cometan en jurisdicciones especiales territoriales o marítimas o en prisiones federales, o en cualesquiera otras prisiones, instituciones o instalaciones en las que las personas se encuentren bajo custodia en virtud de contrato o acuerdo con departamento o agencia federal ${ }^{76}$.

Por lo que respecta a los menores de edad, se castigan los actos sexuales con menores de 16 y mayores 12 años siempre que este último sea al menos 4 años más joven que el autor ${ }^{77}$. La definición de acto sexual (sexual act) se encuentra contenida en el parágrafo 2246 (2) e incluye actos

72 Florida Statutes (2019) Title XLVII. Criminal Procedure and Corrections. Chapter 943 Deparment of Enforcement of Law. Section 943.04354. Removal of the requirement to register as a sexual offender or sexual predator in special circumstances.

73 Cfr. The Supreme Court of the State of Alaska, John Doe v. State of Alaska, Department of Public Safety (2019) 14 june, con respecto a la Alaska Sex Offender Registration Act (ASORA), 2016, con origen en el asunto US Smith et al. v. Doe et. al (2003). También Supreme Court of Pennsylvania, Commonwealth of Pennsylvania v. Jose M. Muniz, 164 A. 3 d. 1189, July 19, 2017.

74 Florida Statutes (2019), Title XLVI. Crimes. Chapter 794. Sexual battery. Section 05. Unlawful sexual activity with certain minors 794.05(1)) y 794.05(3)), respectivamente.

75 Concretamente parágrafos 2241 a 2260A.

76 Véase 18 US Code, Title 8, Part. I, Chapter 109A, § 2243 (a). Sobre la aplicación extraterritorial de la Ley en Estados Unidos, véase DOYLE, C., Extraterritorial application of American Criminal Law, Congressional Research Service, October 31, 2016, pp. 1-73 disponible en https://fas.org/sgp/crs/misc/94-166.pdf

7718 U.S. Code $\$ 2243$ - Sexual abuse of a minor or ward, (a) (1) y (2), respectivamente.

(a) Of a Minor.-Whoever, in the special maritime and territorial jurisdiction of the United States or in a Federal prison, or in any prison, institution, or facility in which persons are held in custody by direction of or pursuant to a contract or agreement with the head of any Federal department or agency, knowingly engages in a sexual act with another person who-

(1) has attained the age of 12 years but has not attained the age of 16 years; and

(2) is at least four years younger than the person so engaging; 
tales como el contacto con el pene y la vulva o con el pene y el ano aunque sea leve; también esa misma modalidad de contacto con penetración, aunque sea leve, o la introducción de dedos u objetos con la intención de abusar, humillar, acosar, degradar o satisfacer el deseo sexual de la persona.

Con respecto a la edad, la norma federal castiga también los tocamientos de los genitales con la misma intención cuando la víctima sea menor de 16 años $^{78}$. El mismo precepto castiga las conductas cuando la persona (sin requisito de edad), se encuentre oficialmente detenida o sometida a cualquier tipo de supervisión, custodia o autoridad disciplinaria $^{79}$. El precepto admite como causa de exclusión de la culpabilidad (defense) el error sobre la edad de la víctima y la existencia de vínculo matrimonial en el momento de comisión de los hechos ${ }^{80}$. Con respecto a la configuración del requisito sujetivo (state of mind proof), la norma exime al Ministerio Público de probar que el acusado conocía la edad de la víctima y la diferencia de edades entre ambos ${ }^{81}$.

Las diferencias de edad entre las modalidades estatales y la federal, a pesar de ser una constante de la regulación y sus reformas, sigue planteando cuestiones muy relevantes por las penas y sobre todo por consecuencias accesorias que lleva aparejada una condena de esta naturaleza. Así lo ha entendido recientemente el Tribunal Supremo de los Estados Unidos en Esquivel-Quintana v. Session, Attorney General (2017) ${ }^{82}$, fallo que ha supuesto una auténtica revolución en los efectos esperados de las

or attempts to do so, shall be fined under this title, imprisoned not more than 15 years, or both.

7818 US Code, Title 8, Part. I, Chapter 109A, § 2246.

(2) the term "sexual act» means-

(A) contact between the penis and the vulva or the penis and the anus, and for purposes of this subparagraph contact involving the penis occurs upon penetration, however slight;

(B) contact between the mouth and the penis, the mouth and the vulva, or the mouth and the anus;

(C) the penetration, however slight, of the anal or genital opening of another by a hand or finger or by any object, with an intent to abuse, humiliate, harass, degrade, or arouse or gratify the sexual desire of any person; or

(D) the intentional touching, not through the clothing, of the genitalia of another person who has not attained the age of 16 years with an intent to abuse, humiliate, harass, degrade, or arouse or gratify the sexual desire of any person;

7918 US Code, Title 8, Part. I, Chapter 109A, $\$ 2243$, (b), (1) y (2).

8018 US Code, Title 8, Part. I, Chapter 109A, \&2243 (c) (1) In a prosecution under subsection (a) of this section, it is a defense, which the defendant must establish by a preponderance of the evidence, that the defendant reasonably believed that the other person had attained the age of 16 years; (2) In a prosecution under this section, it is a defense, which the defendant must establish by a preponderance of the evidence, that the persons engaging in the sexual act were at that time married to each other.

${ }^{81} 18$ US Code, Title 8, Part. I, Chapter 109A, \& 2243 (d) State of Mind Proof Requirement.-In a prosecution under subsection (a) of this section, the Government need not prove that the defendant knew - (1) the age of the other person engaging in the sexual act; or (2) that the requisite age difference existed between the persons so engaging.

82 Esquivel-Quintana v. Session, Attorney General, 30 May 2017581 US. 
condenas por statutory rape en aquellos Estados federados cuya edad es superior a los 16 años.

En Esquivel-Quintana v. Session, Attorney General (2017), el Alto Tribunal discute y resuelve el debate sobre la validez de la edad del statutory rape en el Estado de California para determinar la consecuencia prevista en la Immigration and Nationality Act (INA, 1996) ${ }^{83}$, que no es otra que la expulsión o deportación del territorio norteamericano para extranjeros residentes permanentes. En el asunto resuelto por el Tribunal Supremo, se aborda la problemática de un varón, nacional de México, con residencia permanente en los Estados Unidos que, recién cumplidos los 21 años, mantenía relaciones sexuales con penetración con la víctima, que estaba a punto de cumplir 18 años. Como se ha visto, la regulación federal del statutory rape establece la edad de consentimiento sexual válido en los 16 años, mientras que el Código Penal de California castiga como statutory rape la relación sexual con penetración (sexual intercourse) con un menor (minor) que sea tres años más joven (younger) que el autor ${ }^{84}$. A los efectos de este delito (offense), el Código Penal de California define menor (minor) como la persona que tiene una edad inferior a los 18 años. Por su parte, la Immigration National Act, permite la expulsión de territorio nacional de cualquier extranjero condenado por un delito agravado (agravated felony $)^{85}$, incluyendo el abuso de un menor (abuse of a minor) ${ }^{86}$.

Una vez planteados los términos de la cuestión, la pregunta a la que responde el Tribunal Supremo es la siguiente: ¿qué edad debe tenerse en cuenta para, a efectos federales, entender cometido el delito de abuso a un menor cuando dicho ilícito se define única y exclusivamente en razón de la edad de la víctima (statutory rape)?. Para contestar a ello, el Alto Tribunal recuerda que el delito de abuso sexual a un menor (sexual abuse of a minor) fue incluido en la INA en 1996 como parte de la Illegal Immigration Reform and Immigrant Responsibility Act de 1996 (IIRAIRA) ${ }^{87}$. Por ello, "...en ausencia de una especial relación de confianza (special relationship of trust) una conducta sexual consentida con una pareja joven que cuenta al menos con 16 años no puede ser considerada abuso sexual en los términos de la INA, con independencia de la diferencia de edad entre los participantes». Como consecuencia, no es posible aplicar la consecuencia jurídica de expulsón de territorio nacional prevista en la Immigration and Nationality Act (INA, 1996) a un residente legal por este tipo de ilícito ${ }^{88}$.

83 8 U.S.C. $\$ \S 1101$ (a) (43) (A).

84 Cal. Penal. Code Ann. $\$ 261.5$ (c).

858 U.S.C. $\$ \S 1227$ (a) (2) (A) (iii).

$86 \quad 8$ U.S.C. $\$ \$ 1101$ (a) (43) (A).

87 Illegal Immigration Reform and Immigrant Responsibility Act § 321 (a) (i), 110 Stat. 3009-627.

88 Esquivel-Quintana v. Session, Attorney General, 581 US (2017) 30 May 2017, aludiendo a los mismos argumentos mantenidos en su fallo Gonzales, Attorney General $v$. Duenas-Álvarez, 549 US (2007) 17 January, con respecto a la interpretación de los términos 
Finalmente, y sin entrar a valorar el establecimiento de la edad de consentimiento sexual en los 18 años por parte de un Estado Federal, el propio Tribunal Supremo desliza la existencia de un debate acerca la presunción de abuso en relaciones sexuales cuando una de las personas tiene más de 16 años, con independencia de la diferencia de edad entre ambas. Así lo hace al afirmar: «We leave for another day whether the generic offense requieres a particular age differential between the victim and the perpetrator, and whether the generic offense emcompasses sexual intercourse involving victim over the age of 16 that is abusive because of the nature of the relationship of the participants".

\section{Reino Unido e Irlanda del Norte y República de Irlanda}

El Reino Unido e Irlanda cuentan también con la figura del statutory rape o violación definida por estatuto con ciertas particularidades. En ambos países, como en el resto de los del entorno, se ha procedido a la elevación de la edad de consentimiento sexual en los últimos años, algo que ha reproducido los debates jurídicos y sociales de los Estados Unidos acerca de la idoneidad de la medida.

En el Reino Unido la mayoría de edad se adquiere a los 18 años, de acuerdo con la modificación llevada a cabo por la Family Law Reform de 1969 ${ }^{89}$. Los efectos de esta reforma se extendieron también a Escocia ${ }^{90} \mathrm{e}$ Irlanda del Norte ${ }^{91}$. La edad para contraer matrimonio en Inglaterra, Gales e Irlanda del Norte son los 18 años, aunque es posible hacerlo a los 16 años con el consentimiento parental ${ }^{92}$. En Escocia, por el contrario, no es necesario dicho consentimiento cuando la persona tiene 16 y 17 años ${ }^{93}$.

Reino Unido y Gales cuentan además con una de las edades de responsabilidad penal del menor más bajas de los países del entorno (los 10 años). Escocia ha modificado recientemente la edad elevándola de los 8 a los 12 años $^{94}$. La responsabilidad penal de los menores de 16 años se exi-

theft offense y burglary previstos en el Código de Circulación del Estado de California (Cal. Veh. Code Ann. \$10851(a)) y el 8.U.S.C.\$1101(a)(43)(G);\$1227(a)(2)(A), respectivamente.

89 Family Law Reform Act, 1969, UK Public General Acts, 1969, c. 46, Part. I Reduction of the age of majority and related provisions.

90 Age of Majority Act (Scotland), Act 1969, UK Public General Acts, 1969, c. 39.

91 Age of Majority Act (Northern Ireland), Act 1969, Acts of the Northern Ireland Parliament, 1969, c. 28.

92 Marriage Act, 1949, UK Public General Act, 1949, c. 76. Part II. Restrictions on Marriage. 2. Marriages of persons under sixteen; Marriage Act, 1951, Northern Ireland, Acts of the Northern Ireland Parliament, 1951, C. 25. S. 1.

93 Marriage Scotland Act (1977), UK Public General Act, 1977, c. 15.

94 Age of Criminal Responsibility (Scotland) Act, 2019, Acts of the Scotish Parliament asp 7, Part. I. Age of Criminal Responsibility, 1. Raise of the age criminal responsibility, que modifica la sección 41 de la Criminal Porcedure (Scotland) Act 1995. Aun así, persisten evidentemente las críticas del COMITÉ DE NACIONES UNIDAS CONTRA LA TORTURA, CAT/ C/GBT/CO/6, 
ge a través de un procedimiento denominado Children's Hearing ${ }^{95}$. Esta opción también es factible para menores de hasta 16 años que cometan delitos no graves. Esta situación sigue contraviniendo las recomendaciones del Comité de Derechos del Niño de la ONU que, a pesar de constatar que la edad más común fijada por los Estados son los 14 años, recomienda establecer esa responsabilidad penal en los 15 ó $16^{96}$.

La evolución histórica de la legislación británica refleja también la elevación de la edad de consentimiento sexual. Así, la Criminal Law Amendment Act de 1885 elevó la edad de consentimiento sexual en Reino Unido e Irlanda del Norte de los 13 a los 16 años. La sección 11 de esta reforma, conocida como Enmienda Labouchere, calificaba como gross indecency las relaciones sexuales entre personas del mismo sexo, llegando a castigarlas con pena de cadena perpetua ${ }^{97}$. La Sexual Offences Act de $1956^{98}$ consolidó la criminalización de los comportamientos de naturaleza sexual que estuvieron vigentes hasta el año 2004. La norma, que establecía la figura del statutory rape en su sec. $5^{99}$, mantenía como edad de consentimiento sexual los 16 años, pero establecía excepciones para los comportamientos sexuales llevados a cabo por varón con edad no superior a los 24 años y mujer entre los 13 y los 16 años ${ }^{100}$. Sólo la reforma operada por la conducta Sexual Offences Act de 1967 descriminalizó los comportamientos sexuales de naturaleza homosexual en privado entre varones siempre y cuando ambos hubieran alcanzado la edad de 21 años ${ }^{101}$. La Criminal Justice and Public Order Act de $1994^{102}$ rebajó la edad de consentimiento sexual a los 18 años y finalmente, la Sexual Offences (Amendment) de $2000^{103}$ la estableció en 16 años, equiparando así edad de consentimiento para relaciones heterosexuales y homosexuales.

La Sexual Offences Act (SOA) aprobada en 2003 elevó la edad de consentimiento sexual válido en el Reino Unido a los 16 años. La norma,

CONVENCIÓn contra la tortura y otros tratos o penas crueles, inhumanos y degradantes, Observaciones finales sobre el sexto informe periódico del Reino Unido de Gran Bretaña e Irlanda del Norte, de 7 de junio de 2019.

95 En algunas ocasiones, los menores de 16 y 17 años también pueden ser derivados a este sistema. Veánse las posibilidades en Escocia en HENDERSON, G., Criminal Advice and Remittals to the Children's Hearings System, Scottish Children's Reporter Administration and the Centre for Youth \& Criminal, July, 2017, pp. 1-17.

$96 \mathrm{CRC} / \mathrm{c} / \mathrm{GC} / 24$, Un COMMITTE ON THE RIGHTS OF THE CHILD, General Comment No. 24 on children's rights in the child justice system, 18 septiembre, 2019, parág. 20 y 21.

97 The Criminal Law Amendment Act, 1885, 48 \&49 Vict. C. 69. Chapter L XIX, part. I, s. 5 (1). Véase, BURNIE, R. W., The Criminal Law Amendment Act, 1885, with introduction, commentary and forms of indictments, Waterlow \& Sons, London, 1885, p. 6.

98 Sexual Offences Act 1956, UK Public General Acts 1956, c. 69.

99 Sexual Offences Act 1956, UK Public General Acts 1956, c. 69. Sec. 5 "It is felony for a man to have unlawful sexual intercourse with a girl under the age of thirteen".

100 Sexual Offences Act 1956, UK Public General Acts 1956, c. 69, sec. 6 (3).

101 Sexual Offences Act 1967, Uk Public General Acts 1967, c. 60, sec. 1.

102 Criminal Justice and Public Order Act 1994, UK Public General Acts 1994, c. 33.

103 Sexual Offences (Amendment) 2000, UK Public General Acts 2000, c. 44. 
actualmente en vigor, prevé excepciones si existe relación de autoridad (profesores, supervisores, trabajadores sociales) o estamos ante el llamado «deber de cuidado» (duty of care). En estos casos, la edad de consentimiento se eleva a los 18 años. La figura del statutory rape se establece en la secc. 5. Este precepto castiga a quien mantenga relaciones sexuales con un menor de 13 años ${ }^{104}$, con independencia de que el dolo del autor abarque la edad de la víctima. El error sobre la edad de esta última sólo es admisible en los casos de relaciones sexuales entre menores de edad legal.

La problemática de la tipicidad de las relaciones sexuales entre menores y mayores de edad sexual (menores de 16 años y mayores de esa edad, pero menores de 18) también ha provocado importantes discusiones acerca de los límites y consecuencias del Derecho penal en el desarrollo de la sexualidad de estos colectivos. La sección 13 de la SOA de 2003 prevé la aplicación de sanciones penales que oscilan entre los 6 meses (o multa) y los 5 años de privación de libertad para aquellos casos en los que el sujeto activo menor de 18 años cometa alguna de las conductas previstas en las secciones 9 a 12: mantener relaciones sexuales con un menor, incitar al menor a mantenerlas, mantener relaciones sexuales delante de un menor o hacerle presenciar actos de naturaleza sexual. Cuando la víctima tenga una edad comprendida entre los 13 y los 15 años y el autor sea una persona próxima en edad, el Ministerio Público (Crown Prosecution Service, Director of Public Prosecutions, $D P P$ ) podrá tener en cuenta circunstancias como la edad, el interés general, la naturaleza de la actividad sexual, la disparidad de edades entre sujetos, el desarrollo físico, emocional y educacional entre otros, para decidir acerca de la necesidad de ejercer la acción penal ${ }^{105}$.

El statutory rape o delito de violación definida por estatuto de la sec. 5 de la $S O A$ de 2003 fue declarada constitucional y conforme al art. 6.2 del Convenio Europeo de Derechos Humanos por la Sala de Apelaciones en $R$ v. $G$, de 18 de junio de $2008^{106}$. El acusado, varón de 15 años, fue condenado a una pena de privación de libertad de 12 meses por mantener relaciones sexuales con penetración con la víctima (mujer) que, aunque en el momento de los hechos contaba con 12 años, le había dicho al autor que tenía 15. El argumento central utilizado por el Tribunal para mantener la constitucionalidad del precepto fue que el contenido del art. 6 del CEDH consagra las garantías de una juicio justo y público y la separación de

104 Sec. 5. Rape of a child under 13; Sec. 6. Assault of a child under 13 by penetration; Sec. 7. Sexual Assault of a child under 13; Sec. 8 Causing of inciting a child under 13 to engage sexual activity; Sec. 9 Sexual activity with a child.

105 Cfr. Code for Crown Prosecution-Adult/ Child defendants, Documento disponible en https:/www.cps.gov.uk/legal-guidance/rape-and-sexual-offences-chapter-2-sexualoffences-act-2003-principal-offences-and

$106 \quad R v G$ [2008] UKHL 37; [2009]. 
poderes en los procesos penales y civiles, pero no el contenido particular del derecho substantivo, los elementos objetivos y subjetivos del mismo ${ }^{107}$.

La regulación británica tampoco está exenta de polémica debido a los problemas interpretativos y el solapamiento de las edades de desarrollo sexual. La problemática de las relaciones sexuales entre menores de edad sexual y legal o personas próximas en edad fue, y sigue siendo, uno de los asuntos más complejos de abordar y resolver. En el propio fallo, el Tribunal reconoció que, a pesar de que la sección 5 de la SOA 2003 tiene como finalidad esencial proteger a los menores de 13 años de sí mismos ${ }^{108}$ y de otros, existe el riesgo de estigmatizar como violadores a niños que mantienen relaciones o contactos sexuales entre ellos. Por ello, entiende el órgano judicial que el Ministerio Público $(D P P)$ tiene una gran responsabilidad en la persecución de estas conductas cuando «las dos partes son similares en edad para discriminar entre casos en los que la actividad prohibida era mutuamente consentida por ambas partes y aquellos otros en los que el denunciante fue sometido mediante una situación de explotación o de presión por parte del otro» ${ }^{109}$.

Las críticas sobre la regulación y, especialmente sobre fallos en los que los Tribunales deben entrar de nuevo a juzgar elementos o circunstancias referentes al comportamiento de las víctimas también se han puesto de manifiesto con respecto a la regulación británica. Así, por ejemplo, el fallo $R v$. $C$ (2011), en el que el Tribunal de Apelaciones decidió reducir la pena de dos años de privación de libertad a 6 varones entre los 18 y los 21 años que habían sido condenados por un delito statutory rape. Las víctimas, dos niñas de 12 años con las que habían mantenido relaciones sexuales consentidas, les habían hecho saber que tenían 16 años en el momento de comisión de los hechos ${ }^{110}$.

La regulación de Irlanda resulta especialmente interesante por varias razones. La primera de ellas porque, a pesar de ser un país con un sistema jurídico de corte anglosajón, la figura del statutory rape fue declarada parcialmente inconstitucional en el año 2006. La segunda porque en los dos últimos años el país ha experimentado una serie de reformas legislativas, consecuencia de la adaptación de la Directiva Comunitaria

$107 R v G$ [2008] UKHL 37; [2009], parág. 4, que reproduce fallos previos del Tribunal en la misma materia: Matthews v Ministry of Defence [2003] UKHL 4; [2003] 1 AC 1163, Z $v$ United Kingdom (2001) 34 EHRR 97, R v Gemmell [2002] EWCA Crim 1992; [2003] 1 Cr App R 343, 356 y STEDH Salabiaku c. Francia, (Dec. 10519/83).

${ }_{108} R v G$ [2008] UKHL 37; [2009], parág. 14, reproduciendo en este aspecto el razonamiento mantenido en $R v$ Corran [2005] EWCA Crim 192, parág. 6

109 R v G [2008] UKHL 37; [2009], parág. 14. Sobre la discrecionalidad del Director of Public Prosecutions, DPP, veáse el fallo In Re (on the application of F) v DPP (2013) EWHC 945 (Admin), 24 May.

110 Véanse las observaciones al respecto de STEvenson, K., "It is what Girls of indifferent character do... Complications concerning the Legal age of consent in the light of R v. C (2011)», Journal of Criminal Law, vol. 76, 2012, pp. 130-139. 
2011/92, de 13 de diciembre, y ha elevado la edad de consentimiento sexual a los 17 años. La tercera porque la aprobación de la Health (Regulation of Termination of Pregnancy) Act ${ }^{111}$ en 2018 ha supuesto un cambio fundamental en materia de interrupción voluntaria del embarazo y la derogación de la Enmienda VIII Constitución Irlandesa ${ }^{112}$.

La mayoría de edad en Irlanda se adquiere a los 18 años ${ }^{113}$, mientras que la edad de responsabilidad penal del menor se sitúa en los 12 años tras la aprobación de la Criminal Justice Act de $2006^{114}$. Por lo que se refiere a la edad de consentimiento sexual actualmente se sitúa en los 17 años, algo que la convierte en una de las más elevadas de la Unión Europea sólo superada por Malta (18 años). Los 18 años son también la edad establecida para poder contraer matrimonio heterosexual $\mathrm{u}$ homosexual en Irlanda ${ }^{115}$.

Los delitos contra la libertad e indemnidad sexual se regulan actualmente en la Criminal Law (Sexual Offenses Act) de 2017116, resultado de la transposición de la Directiva UE 2011/92/UE, de 13 de diciembre. Esta nueva ley sustituyó a la Criminal Law (Sexual Offences) Act de 2006, aprobada como consecuencia de la declaración de inconstitucionalidad del statutory rape de la Criminal Law Amendment Act de 1935. En C.C v. Ireland \& ors (2006) $)^{117}$ el Tribunal Supremo irlandés analizó la condena de un varón de 19 años que había mantenido relaciones sexuales con una mujer menor de 15 años, pero que había manifestado en todo momento al autor que tenía $16^{118}$.

La ley de 1935 que castigaba las relaciones sexuales con penetración (carnal knowledge) con mujer menor de 15 años $^{119}$. La redacción del tipo no admitía el error sobre la edad de la víctima como causa de exclusión de la antijuridicidad de la conducta. A esta circunstancia había que aña-

111 Health (Regulation of Terminantion of Pregnancy) Act, 2018.

112 La derogación se llevó a cabo a través de la Thirty Sixth Amendment of the Constitution Act of 2018, que introdujo el nuevo artículo 40.3.3 de la Constitución.

113 Age Majority Act, 1985, c. 2 (1) a.

114 Criminal Justice Act, 2006. Esta norma modificó la sección 52 (1) de la Children Act de 2001 y elevó la edad de responsabilidad penal del menor de los 7 a los 12 años. En apartado (2) de la sección 52 establece también la presunción de inimputabilidad de los menores entre los 12 y los 14 años.

115 Marriage Act 2015 (No. 35, 2015), 22 October, que legalizó el matrimonio entre personas del mismo sexo en Irlanda tras la celebración del referéndum celebrado ese mismo año.

116 Criminal Law (Sexual Offenses Act) de 2017.

117 C.C v. Ireland \& ors [2006] 4 IR 1, 23 May 2006.

118 La decisión revoca el fallo previo del Tribunal CC v. Ireland [2005].

119 Criminal Law Amendment Act de 1935, 28 febrero. El precepto literalmente establecía lo siguiente: "Any person who unlawfully and carnally knows any girl under the age of fifteen years shall be guilty of a felony, and shall be liable on conviction thereof to penal servitude for life or for any term not less than three years or to imprisonment for any term not exceeding two years». 
dir que, desde la entrada en vigor de la Sex Offenders Act de 2001, la condena por un delito de esta naturaleza implicaba necesariamente su inscripción en el Registro de Delincuentes Sexuales con posibles efectos de naturaleza punitiva sobre el condenado ${ }^{120}$. En C.C v. Ireland \& ors (2006), el Alto Tribunal Irlandés declaró inconstitucional el statutory rape de la Ley de 1935 por vulneración de los arts. 38 (derecho fundamental a un proceso con todas las garantías) y 40 (derechos fundamentales del ciudadano: libertad y privacidad) de la Constitución Irlandesa, pero también, y al contrario que el Reino Unido, del art. 6 del CEDH (Véase supra) ${ }^{121}$.

La Criminal Law (Sexual Offences) Act de 2006 siguió manteniendo la edad de consentimiento sexual en los 15 años y, por tanto, considerando típicas las relaciones sexuales con un menor de esa edad siempre que no existiera vínculo matrimonial. La ley aceptaba como causa de exclusión de la culpabilidad la «creencia honesta» de que la persona era mayor de 15 años ${ }^{122}$. La misma ley tipificaba los comportamientos cuando la víctima era menor de 17 años si entre el autor y la víctima existía acusado «relación de autoridad» (padres, padrastos, curadores, cuidadores, profesores, supervisores) $)^{123}$.

La aprobación de la Criminal Law (Sexual Offenses Act) de 2017 eleva la edad de consentimiento sexual a los 17 años y establece dos tipos penales atendiendo a la edad de la víctima. El primero castiga los actos de naturaleza sexual con menores de 15 años (sección 16) y el segundo con menores de 17 años, pero mayores de 15 (sección 17). En ambos casos, la norma admite como causa de exclusión de la culpabilidad el error (reasonable mistake) sobre la edad de la víctima (secs. 16 y 17 (3)). Para ello, el Tribunal atenderá a todas las circunstancias del hecho y establecerá como estándar probatorio el fijado en los procedimientos civiles. Por lo que se refiere al consentimiento de la víctima como causa de exclusión de la antijuridicidad, no se admite cuando la víctima es menor de 15 años (sección $16(6))^{124}$, pero sí cuando tiene una edad comprendida entre los 15 y

120 Sobre el contenido de esta norma en su redacción original, véase CoTTER, A. I Doyle, U. / Linnane, P., "Sex Offenders Act, 2001: Implications for the Probation and Welfare Service, Policy and Practice», Irish Probation Journal, vol. 2-1, 2005, pp. 78-83.

121 En detalle sobre los fallos, Prendergast, D., "Strict Liability and the Presumption of Mens Rea after CC v. Ireland», Irish Jurist, vol. 46, 2011, pp. 211-220; EL MISMO en "The constitutionality of strict liability», Dublin University Law Journal, 2011, vol. 33, pp. 285-318; Dickson, B., The Irish Supreme Court: historical and comparative persepectives, Oxford University Press, Oxford, 2019, pp. 214-215 y Hamilton, C., "The Presumption of Innocence in Irish Criminal Law: Recent Trends and Possible Explanations», Irish Journal of legal Studies, vol. 2-1, 2011, pp. 3-21.

122 Criminal Law (Sexual Offences) Act 2006, sec. 2.

123 Criminal Law (Sexual Offences) Act 2006, sec. 3.

124 Sexual act with child under 15 years of age. secc. 16 (6) "It shall not be a defence to proceedings for an offence under this section for the defendant to prove that the child against whom the offence is alleged to have been committed consented to the sexual act of which the offence consisted.» 
los 17 años si concurren una serie de circunstancias. En primer lugar, que el acusado sea más joven o, aun siendo mayor que la víctima, la diferencia de edad entre ambos no sea superior a dos años (sección 17, (8) (a)). Este precepto permite sacar de la órbita del Derecho penal las relaciones sexuales consentidas entre menores de edad sexual y mayores de edad sexual y legal, si bien con una diferencia de edad de hasta 2 años (proximidad en edad). En segundo lugar, que no exista relación de autoridad con respecto al menor en el momento de comisión de los hechos (sección 17, (8) (b)). Finalmente, que no exista intimidación o explotación por parte del mayor de edad (sección 17, (8) (c)). En todos los casos el precepto exige además autorización previa del Ministerio Público (Director of Public Prosecutions) para poder ejercer la acción penal ${ }^{125}$.

La Ley de 2017 ha sido modificada por la Criminal Law (Sexual Offences) (Amendment) Bill de 2018, firmada en 26 de febrero de 2019126. Sus dos objetivos principales han sido la reforma parcial de las secciones (1) y (2) de la Punishment of Incest Act de 1908 y la adición de una nueva sección a la Criminal Law (Sexual Offenses Act) de 2017. Por lo que se refiere a la primera (Ley de Incesto de 1908) se ha sustituido la pena máxima prevista hasta entonces para el delito de incesto (10 años de prisión) por prisión permanente cuando lo cometa el varón ${ }^{127}$. Además, castiga a la mujer (female person) de 17 años o mayor que consintiera el acceso carnal (carnal knowledge) con su abuelo, padre, hermano o hijo. El tipo penal sustituye la nulidad del consentimiento de la mujer por su castigo cuando, siendo mayor de esa edad, consienta la conducta de incesto ${ }^{128}$. Por lo que se refiere a la reforma de la Ley de 2017, se introduce una nueva sección 57 que articula mecanismos específicos de revisión y suspensión de la condena, así como de cumplimiento mínimo de penas. Estas medidas son aplicables sólo a sujetos reincidentes mayores de 18 años.

\section{Canadá}

De manera similar a los Estados Unidos, Canadá presenta algunas particularidades al ser una federación compuesta por provincias y territorios, que son quienes determinan la mayoría de edad. En los Terri-

125 Sexual act with child under 17 years of age. secc. 17 (7).

126 Véase houses of OIREACHTAS, Criminal Law (Sexual Offences) (Amendment) Bill, 2018, Explanatory Memorandum, documento disponible en https://data.oireachtas.ie/ie/ oireachtas/bill/2018/93/eng/memo/b9318d-memo.pdf

127 Punishment of Incest Act de 1908, sec. 1. Incest by Males.

128 Punishment of Incest Act de 1908, sec. 2. Incest by Males. La redacción actual es la siguiente: "Any female person of or above the age of 17 years, who with consent permits her grandfather, father, brother or son to have carnal knowledge of her (knowing him to be her grandfather, father, brother or son, as the case may be), shall be guilty of an offence and shall be liable on conviction on indictment to imprisonment for a term not exceeding 10 years». 
torios del Noroeste y Nunavut y Yukon la mayoría de edad se adquiere a los 19 años ${ }^{129}$. También en las provincias de la Columbia Británica, Nueva Escocia y Terranova y el Labrador ${ }^{130}$. Por el contrario, en Alberta, Manitova, Quebec, Ontario, la Isla del Príncipe Eduardo y Saskatchawen, la mayoría de edad se adquiere a los 18 años ${ }^{131}$.

La norma para contraer matrimonio es de naturaleza federal de acuerdo con la Constitución Canadiense de $1867^{132}$. Así, la Civil Marriage Act de 2005 fue modificada en 2015 y elevó la edad a los 16 años ${ }^{133}$. Por su parte, la edad de responsabilidad penal del menor en Canadá se sitúa en los 12 años. Los delitos cometidos por menores comprendidos entre esa edad y los 17 años son sancionados por la Youth Criminal Justice Act (YCJA) de $2003^{134}$, que derogó a su vez la Young Offenders Act (YOA), en vigor desde $1984^{135}$.

Con respecto a los delitos sexuales, hasta el año 2008 la validez del consentimiento sexual se situaba en los 14 años, edad establecida en $1890^{136}$. La Tackling Violent Crime Act de 2008, que modificó el Código Penal Canadiense, elevó la edad para prestar consentimiento sexual válido de los 14 a los 16 años. Los ejes principales de esa reforma se recogen de manera clara en su sumario: (a) la creación de dos nuevos tipos penales relativos a la utilización de armas de fuego; (b) el endurecimiento de la libertad bajo fianza (bail) por ese tipo de delitos; (c) la efectividad de las sentencias y el control de los delincuentes peligrosos y de alto riesgo; (d) la introducción de un nuevo régimen de detección e investigación de

129 Consolidation of the Age of Majority Act, Revised Statutes of Northwest Territories, 1998, c. A-2 S. 2 y Revised Statutes of the Yukon, 2002, Age of Majority Act, s.1 (1).

${ }_{130}$ RS British Columbia, Age of Majority Act, 1996, cuyo apartado 1 fue modificado el 15 de abril de 1970, rebajado la mayoría de edad de los 21 a los 19; Nova Scotia Age of Majority Act. Chapter 4 of the Revised Statutes, 1989, An Act respecting the Age of Majority, R.S., c, 4, s. 1, 2 (1) y Newfoundland and Labrador Age of Majority Act, 1995, Chapter A-4.2. s. 2.

131 Alberta Age of Majority Act, Chapter A-6, 1; Manitova, Age of Majority Act, 1998, C.C.S.M c. A7, s.1; Quebec Civil Code, 2007, s. 153; Ontario, Age of Majority and Accountability Act, R.S,O, 1990, Chapter A. 7 s.1; Prince Edward Island, Age of Majority Act, 2003, s.1; Saskatchawen, Age of Majority Act, R.S.S, 1978 c. A-6, s. 2 (1) y Saskatchawen, Age of Majority Act, R.S.S, 1978 c. A-6, s.2 (1).

132 En el mismo sentido, la Charter of Fundamental Rights and Freedoms (Constitution Act 1982) que en su sección 15 garantiza el derecho a la igualdad y a la protección sin que pueda producirse discriminación de algún tipo.

133 Civil Marriage Act, S.C. 2005, c. 33, de 20 de julio de 2005, modificada por el c. 29 , s. 4 de la reforma de 18 de Junio de 2015. Secc. 2.2 "No person who is under the age of 16 years may contact marriage».

134 Youth Criminal Justice Act, S.C. 2002, c. 1, modificada en el 2012.

135 Young Offenders Act, R.S.C, 1985, c. Y-1, en vigor hasta el 1 de abril de 2003.

136 La evolución histórica de la edad de consentimiento sexual puede consultarse en el análisis de la tramitación de la reforma realizado por MAcKAY, R., Bill C-22: An act to amend the criminal code (age of protection) and to make consequential amendments to the criminal records Act, Legislative Summary, Parliamentary Information and Research Service, Library of Parliament, Ottawa, 2007, pp. 1-17. 
la conducción bajo los efectos de las drogas, así como el endurecimiento de las penas asociadas a estos delitos y (e) el aumento de la edad de consentimiento sexual de los 14 a los 16 años ${ }^{137}$.

Los delitos sexuales se encuentran regulados en la Parte V del Código Penal Canadiense, bajo la rúbrica Sexual Offenses, Public Morals and Disorderly Conducts ${ }^{138}$. La sección 151 (Sexual interference) castiga cualquier tipo de contacto sexual directo o indirecto que se produzca con partes del cuerpo o con objetos siempre que la víctima sea menor de 16 años. También a quien, con propósito sexual, invite, proponga o incite a una persona menor de 16 años a llevar a cabo la conducta descrita en la sección anterior (sección 152, invitation to sexual touching).

El consentimiento sexual de un menor de 16 años no se admite, con carácter general, como causa de exclusión de la antijuridicidad (sec. 150.1 (1)). Sin embargo, sí que se prevén algunas excepciones atendiendo a la edad del autor y el denunciante y las posibles diferencias de edad entre ambos (close in age exceptions). En primer lugar, la sección. 150.1 (2) se permite aplicar la excepción cuando estamos ante menores con edades comprendidas entre los 12 y los 13 años (exception for complainant aged 12 or 13). En este tipo de casos, el consentimiento es válido salvo si la víctima tiene 12 años o más pero menos de 14 (2.a) y el acusado no es mayor de 2 años y no existe una relación posición de autoridad o confianza; el autor no es una persona con quien la víctima tenga una relación de dependencia o se trata de situaciones consideradas de explotación (2.b). Lo que se busca con ello es no criminalizar las conductas sexuales entre menores de edad, como claramente vuelve a reflejar el apartado $3^{139}$.

En segundo lugar, el consentimiento se entenderá también válido si el denunciante tiene 14 o más años, pero menos de 16 y el autor no es mayor de 5 años (sec. 150.1.2.1. a)), ni ostenta una posición de confianza o autoridad ni existe una relación de dependencia o situación de explotación (Sec. 150.1.2.1.b)). Por situaciones de explotación se entienden la prostitución, la pornografía, aquéllas que tienen lugar en el marco de una relación de dependencia o confianza, pero también cuando existe una diferencia de edad significativa entre la persona de menor edad y su pareja e incluso si se lleva a cabo a través de formas

137 Tackling violent Crime Act S.C. 2008, c. 6. Véase el interesante estudio empírico sobre el impacto de la reforma durante sus primeros años realizado por MiLLER, B. B. / Cox, D. N. / SAEWYC, E. M., "Age of sexual consent in Canada: Population-based evidence from law and policy», The Canadian Journal of Human Sexuality, vol. 19-3, 2010, pp. 105-117.

138 Canadian Criminal Code, R.S.C, 1985, C-46.

139 "Exception for accused ages twelve and thirteen: "No person shall be tried for an offence under section 151 or 152 or subsection 173(2) unless the person is in a position of trust or authority towards the complainant, is a person with whom the complainant is in a relationship of dependency or is in a relationship with the complainant that is exploitative of the complainant». 
o medios que tienden a controlar o a influenciar al menor (Internet, de forma secreta...). En estos casos el consentimiento se reputa valido a $\operatorname{los} 18$ años $^{140}$.

La modificación de la edad de consentimiento sexual llevó consigo la previsión de dos excepciones expresamente previstas en la sección. 150.1 (2.2) letras a) y b) y 150.1 (2.3). Son llamadas exceptions for transitional purpouses y contemplan la validez del consentimiento del menor de 16 años en aquellas situaciones que pudieran estarse produciendo con anterioridad o en el momento de entrada en vigor de la modificación legal. En estos casos, el consentimiento se reputará válido si, aun siendo la diferencia de edad superior a 5 años, nos encontramos ante relaciones similares o asimilables a la pareja o han cohabitado en una relación análoga a la conyugal por un periodo inferior a un año o han estado o se encuentran a la espera de un hijo como resultado de esa relación. Del mismo modo, si el acusado es una persona son posición de autoridad o dependencia o pero se da una situación de explotación. Por su parte, la excepción prevista en el apartado 2.2, permite alegar como causa de exclusión de la antijuridicidad la existencia de matrimonio celebrado el día inmediatamente después del que la reforma entra en vigor.

La sección 150.1 (4) regula el error sobre la edad del menor de 16 años. Con carácter general, no se admite como causa de exclusión de la culpabilidad excepto cuando el acusado hubiera realizado todo los actos o pasos razonables para determinar la edad de la víctima. La misma redacción rige para el error en aquellos tipos penales en los que la víctima sea menor de 18 años pero mayor de 16 (sección 150.1 (5)).

Aunque en Canadá los 16 años eran la edad de consentimiento sexual válido aplicado a todo tipo de modalidades sexuales, hasta la reforma de 15 de noviembre de 2016, la edad de consentimiento sexual para la práctica de penetración anal eran los 18 años, salvo que se llevara a cabo dentro del matrimonio heterosexual. Así se establecía en la sección 159 (1) (Anal intercourse) y (2 a, b) (Exceptions). Este precepto fue declarado contrario a la Charter of Fundamental Rights and Freedoms y finalmente derogado.

140 Con respecto al impacto de la close in age exception en los procedimientos penales, véase el interesante estudio de la jurisprudencia de los Tribunales canadienses en la materia entre 2014 y 2016 (ambos años incluidos) realizado por GRANT, I. / BENEDET , J., «The Statutory Rape Myth: A Case Law Study of Sexual Assaults against Adolescent Girls, Canadian Journal of Women and Law, vol. 31, 2019, pp. 266-292. En él se analizan 510 asuntos en los que se enjuician 625 denuncias de mujeres con edades comprendidas entre los 12 y los 17 años incluidos. 


\section{Conclusiones}

La elevación de la edad de consentimiento sexual válido para los menores de edad ha sido un constante en los países del entorno en los últimos años. En el ámbito de la UE, la justificación formal parece residir en la necesaria transposición del contenido del Directiva 2011/93/ UE, del Parlamento Europeo y del Consejo, de 13 de diciembre, relativa a la lucha contra los abusos sexuales y la explotación infantil. La prevención de esas dos conductas (abuso sexual y explotación) es la razón que lleva los Legisladores del entorno a articular además Registros de Delincuentes Sexuales en los que se inscriben las condenas por este tipo de delitos. Su funcionamiento, efectos y régimen de cancelación de antecedentes dista mucho del previsto en los códigos penales, amplificando los efectos punitivos de la sanción penal.

Desde el punto de vista de la configuración de los tipos penales, la elevación de la edad de consentimiento sexual de los menores produce además una serie de efectos a priori no deseados. En primer lugar, la posible afectación de los derechos fundamentales de libertad y privacidad del propio menor de edad, derechos en los que se incardina propia la libertad sexual. En segundo lugar, la criminalización de comportamientos entre menores de edad sexual y menores de edad legal, pero a su vez responsables penalmente conforme a las leyes de responsabilidad penales de los menores. En tercer lugar, la criminalización de comportamientos sexuales que se producen entre menores adultos y adultos jóvenes por el propio solapamiento de las edades de desarrollo fisiológico y sexual.

Para poder hacer frente a los efectos derivados de la elevación del consentimiento sexual, la propia Directiva EU 2011/93/UE incluye una posibilidad de que los Estados Miembros contemplen circunstancias tales como la proximidad en edad y desarrollo o madurez de las partes en el comportamiento sexual como causa de exclusión de la responsabilidad del mayor de edad legal. En el caso español, el Legislador decidió incluir esa cláusula en el actual art. 183 quáter del Código Penal. Su existencia en los países del entorno, especialmente en los sistemas anglosajones, cuenta con una larga tradición y desarrollo, a pesar de que las interpretaciones de las últimas décadas parecen retrotraer a alguna una de las principales razones de su inclusión hace más de un siglo: la prevención de embarazos no deseados de la mujer soltera.

En los sistemas de Derecho penal anglosajón la figura del statutory rape o delito de violación definida por estatuto es una pieza esencial en la materia que nos ocupa. El tipo penal, configurado a su vez como delito de responsabilidad objetiva (strict liability offense), castiga a quien mantenga relaciones sexuales con penetración (sexual intercourse) con una persona a la que no se reconoce capacidad de consentimiento sexual válido. Para ello, se establece como criterio objetivo la edad de víctima. La edad, sobre la que en términos generales no se admite error, no tiene 
por qué ser abarcada por el dolo del autor, bastando un dolo genérico para entender realizada la conducta. Esa edad son los 13 años en Reino Unido, los 16 años en el Sistema Federal Norteamericano, los 14, 15, 16 ó 17 en algunos Estados federados de los Estados Unidos e incluso los 17 años en Irlanda.

Sin embargo, a pesar de la existencia de un delito de responsabilidad objetiva, los sistemas anglosajones han articulado dos mecanismos para «suavizar» los efectos de las severas consecuencias jurídicas que llevan aparejadas ese tipo de comportamientos. Por un lado, algunos de ellos admiten error sobre la edad de la víctima sólo en aquellos casos en los que el sujeto activo (mayor de edad legal) y el sujeto pasivo (menor de edad sexual) son próximos en edad y el sujeto activo ha mostrado una conducta diligente con respecto a la comprobación de la edad de la víctima. En esos casos, la existencia de error no elimina por completo la culpabilidad del autor, pero sí permite imponer una pena muy inferior a la prevista a través de la calificación de la conducta como delito leve (misdemeanor). Los efectos no acaban ahí porque la propia calificación de la conducta como delito leve impide la inscripción de la condena penal en el correspondiente Registro de Delincuentes Sexuales. Por el contrario, cuando estamos ante relaciones sexuales con penetración llevadas a cabo por dos menores de edad legal, pero uno de ellos sujeto a responsabilidad penal conforme a la normativa de menores y, a su vez, con edad de consentimiento sexual válido, los sistemas anglosajones articulan un mecanismo de exclusión de responsabilidad de la conducta. Ello se hace a través del reconocimiento de la validez del consentimiento del menor y, por tanto, de la antijuridicidad de la conducta (unlawfulness). Esta técnica es la que se ha venido tradicionalmente conociendo como cláusula Romeo y Julieta. La particularidad de los sistemas penales anglosajones reside en que, en ambos casos, el propio tipo penal establece numéricamente la diferencia de edad admisible entre las partes.

La situación descrita anteriormente no resuelve por completo el problema que se plantea en los países anglosajones con las relaciones sexuales entre personas mayores de edad legal y menores de edad sexual como consecuencia de elevación de la edad consentimiento sexual. La propia configuración del statutory rape como delito de responsabilidad objetiva obliga en estos casos a excluir por completo el conocimiento que tiene el autor de la edad de la víctima. Como ha señalado una gran parte de la Doctrina anglosajona, la figura del statutory rape sirve para proteger la indemnidad del menor de edad siempre y cuando la edad sea relativamente baja (12 ó 13). Sin embargo, elevación de esa edad a los 14, 15, 16 e incluso 17 años como ocurre en algunos Estados federados de los Estados Unidos e Irlanda, tiene unas consecuencias absolutamente desproporcionadas con respecto al desvalor de la conducta no sólo por la propia pena en sí, sino por los efectos de la inscripción en los Registros de Delincuentes Sexuales. Ello obliga en 
muchas ocasiones a los Tribunales a enjuiciar atendiendo a circunstancias relativas a la propia relación sexual entre los miembros; al nivel educativo, social e incluso económico de ambos; a la existencia de relaciones sexuales previas por parte del miembro a quien no se presume consentimiento sexual válido e incluso, a de quién es la iniciativa de la relación sexual.

El establecimiento de edades de consentimiento sexual no es un tema exento de polémica. El desarrollo de la sexualidad unido al solapamiento de etapas madurativas no es un debate pacífico, máxime cuando el problema de fondo sigue siendo el encaje consciente o inconscientemente de los delitos sexuales bajo la rúbrica invisible de los delitos contra la moral. Dentro de ese marco, se asume a priori que toda relación con un menor implica cierto grado de coerción porque las partes no se encuentran en una situación de igualdad. Para algunos autores esta postura permite recuperar el fundamento histórico de la prohibición de la conducta, que no es otro que la prevención de los embarazos no deseados de la mujer soltera y, en menor medida, del riesgo de afectación de la salud del menor por la posible contracción de enfermedades de transmisión sexual con parejas sexuales de mayor edad. La cuestión que inevitablemente surge entonces es si, incluso buscando prevenir esos dos efectos, es razonable, adecuado y, sobre todo legítimo utilizar el Derecho penal para ello.

\section{Bibliografía}

American Law institute, Model Penal Code. Official Draft and Explanatory Notes. Complete Text of Model Penal Code as adopted at the 1962 Annual Meeting of the American Law Institute at Washington, D.C., May 24, 1962, Philadelphia.

ANNITO, M., "Consent searches of minors», New York University Review of Law and Social Change, vol. 1, 2014, pp. 1-51.

Bullough, V. L. / Graupner, H., Adolesence, sexuality and Criminal Law. Multidisciplinary perspectives, First Edition, Taylor Francis Group, New York, 2006.

Bunting, L. / Colette Mcauley, C., «Teenage pregnancy and parenthood: the role of the fathers", Child \& Family Social Work, vol. 9-3, 2004, pp. 295-303.

Burnie R. W., The Criminal Law Amendment Act, 1885, with introduction, commentary and forms of indictments, Waterlow \& Sons, London, 1885.

CARPENTER, L., "On statutory rape, strict liability and the public welfare offense model», American University Law Review, 53, 2003, pp. 313391. 
Carpenter, B. / O’Brien, E. / Hayes S. / Death, J., «Harm, responsibilty, age and consent», New Criminal Law Review, vol, 17- 1, 2014, pp. 2354.

Christopher, R. L. / CHRistopher, K.H., «The paradox of statutory rape», Indiana Law Review, 2012, vol. 87, 2012, pp. 505-549.

Conford, A., «Preventive criminalization», New Criminal Law Review, 18, 2015, pp. 1-34.

Cotter, A. / Doyle U. / Linnane, P., «Sex Offenders Act, 2001: Implications for the Probation and Welfare Service, Policy and Practice», Irish Probation Journal, vol. 2-1, 2005, pp. 78-83.

Denno, D. W., «Why the Model Penal Code's Sexual Offense Provisions should be pulled and replaced», Ohio State Journal of Criminal Law, vol. 1-1, 2003, pp. 207-218.

Dickson, B., The Irish Supreme Court: historical and comparative perspectives, Oxford University Press, Oxford, 2019.

Dehart, G. F., «Comity, Conventions, and the Constitution: State and Federal Initiatives in International Support Enforcement», Family Law Quarterly, vol. 28-1, 1994, pp. 89-115.

Doyle, C., Juvenile Delinquents and Federal Criminal Law: The Federal Juvenile Delinquency Act and Related Matters, Congressional Research Service, 6 Nov, pp. 1-23, 2018, disponible en https://fas.org/sgp/crs/ misc/RL30822.pdf

- Extraterritorial application of American Criminal Law, Congressional Research Service, October 31, pp. 1-73, 2016 disponible en https://fas. org/sgp/crs/misc/94-166.pdf

Fischel, J. J., «Per se or Power?, Age and sexual consent», Yale Journal of Law and Feminism, vol. 22-2, 2010, pp. 279-341.

Fischel, J. J. / O’CONNEL, H. R., «Disabling consent, or reconstructing sexual autonomy», Columbia Journal of Gender and Law, vol. 30- 2, 2015, pp. 428-528.

Fletcher, G. P., «Dogmas of the Model Penal Code», Buffalo Law Review, vol. 2-3, 1998-1999, pp. 3-24.

Finder, S. / KoReman, S., «Community, context, and the contrasting roles of clinicians and researchers: challenges raised by statutory rape», American Journal of Bioethics, vol. 14-10, 2014, pp. 55-57.

Grant, I. / BenEDET, J., «The Statutory Rape Myth: A Case Law Study of Sexual Assaults against Adolescent Girls, Canadian Journal of Women and Law, vol. 31, 2019, pp. 266-292.

Graupner, H., "Love versus abuse: Crossgenerational sexual relations of minors: a gay rights issue?», Journal of Homosexuality, vol. 37-4, (1999), pp. 23-56. 
- "Sexual consent. The Criminal Law in Europe and overseas», Archives of Sexual Behaviour, october, vol. 29-5, 2000, pp. 415-461.

GREEN, S. P., «Prototype Theory and the classification of offenses in a revised Model Penal Code», Buffalo Criminal Law Review, vol. 4-1, 2000-2001, pp. 301-304.

Higginson, J. C., «Defining, excusing, and justifying deviance: teen mothers's account for statutory rape», Symbolic Interaction, vol. 22 $-1,1999$, pp. 25-44.

GuERRINA, B., "Mitigating punishment for statutory rape», University of Chicago Law Review, Fall vol. 65-4, 1998, pp. 1251-1278.

INTER-AMERICAN COMMISSION OF HUMAN RIGHTS., The situation of Children in the Adult Criminal Justice system in the United States, Washington D.C, 1 Mar. 2018 (OAS/Serv. L/V/II Doc. 34/18).

Hamilton, C., «The Presumption of Innocence in Irish Criminal Law: Recent Trends and Possible Explanations», Irish Journal of legal Studies, vol. 2-1, 2011, pp. 3-21.

Hamilton, V. E., «Principles of Family Law», Fordham Law Review, vol. 75- 1, 2006, pp. 31-73.

Harris, A. J. / Lobanon-Rostovsky, C. / Levenson, J. S., «Widening the Net: the effects of transitioning to the Adam Walsh Act's Federally Mandated sex offender classification system», Criminal Justice and Behavior, vol. 37-5, 2010, pp. 503-519.

Heilbrun, K. / De Matteo, D. / KInG, C. / Filone, S., Evaluating Juvenile Transfer and Disposition: Law, Science, and Practice, Routledge Taylor and Francis Group, New York and London, 2017.

Henderson, G., Criminal Advice and Remittals to the Children's Hearings System, Scottish Children's Reporter Administration and the Centre for Youth \& Criminal, July, 2017, pp. 1-17.

Kadish, S. H. / Schulhofer, S. J. / Steiker, C. S., Criminal Law and its processes. Cases and materials, $8^{\text {th }}$ edition, Wolter Kluwers, New York, 2007.

LAUER, R. J., «Fourteenth Amendment- Statutory rape: protection of minor female and prosecution of minor male», The Journal of Criminal Law and Criminology», vol. 72, 1981, pp. 1374-1392.

LAW REFORM COMMISSION, Report: Sexual offences and capacity to consent, Dublin, 2013.

LEE, S., "Child's voice vs. parent's control: resolving the tension between the Convention on the rights of the child and U.S Law», Columbia Law Review, vol. 117- 3, 2017, pp. 687-728. 
Leigh, L. / Rockoff, J. E., "Estimates of the Impact of Crime Risk on Property Values from Megan's Laws.» American Economic Review, vol. 98-3, 2008, pp. 1103-1127.

MackAY, R., Bill C-22: An act to amend the criminal code (age of protection) and to make consequential amendments to the criminal records Act, Legislative Summary, Parliamentary Information and Research Service, Library of Parliament, Ottawa, 2007, pp. 1-17.

MARTínez Guerra, A., "Notas sobre el Registro de delincuentes sexuales», Revista de Actualidad Criminológica, vol. 4, 2016, pp. 46-52.

Marco Francia, M. P., "La inscripción en el Registro de Delincuentes Sexuales, una pena de inhabilitación especial contraria al principio de legalidad. A propósito de la Sentencia núm. 37/2018 del Juzgado de lo Contencioso-Administrativo núm. 3 de Zaragoza», La Ley, vol. 9256, 2018, pp. 1-10.

Matevia T. C., "Sex offenses and Penal Code Revision in Michigan», Wayne Law Review, Summer, vol. 14-3, 1967-1968, pp. 934-985.

MAYNARD, R. A (ed.), Kids having kids, The economic costs and social consequences of teen pregnancy, Routledge, New York, 1997.

Miller, B. B. / Cox. D. N. / SAEwyc, E.c., "Age of sexual consent in Canada: Population-based evidence from law and policy», The Canadian Journal of Human Sexuality, vol. 19-3, 2010, pp. 105-117.

Minow, M., «We, the Family: Constitutional Rights and American Families», The Journal of American History, vol. 74-3, The Constitution and American Life: A Special Issue, Dec.,1987, pp. 959-983.

Molina BlázQuez, C., «A propósito de la constitucionalidad del Real Decreto 110/2015, que regula el registro de delincuentes sexuales», $L a$ Ley Penal: Revista de Derecho Penal, Procesal y Penitenciario, vol. 119, 2016 pp. 1-15.

Moore, M.M., Causation and responsibility: an Essay in Law, Morals, and the Metaphysics, Oxford University Press, Oxford, 2014.

Olsen, F., "Statutory rape: a feminist critique of the rights analysis», Texas Law Review, vol. 63, 1984, pp. 394-432.

OuderkeK B. A. / FARR, R. H. / Reppucci, N. D., "Defining sexual abuse victimization and revictimization. Is love or sexual abuse? Young adults'perceptions of statutory rape», Journal of Child Abuse, vol. 22, 2013, pp. 858-877.

PEARLSTEIN, L., «Walking the tightrope of statutory rape law: using International legal standars to serve the best interest of juveline offenders and victims», American Criminal Law Review, vol. 47, 2010, pp. 109128. 
Petroni, S. / Das, M. / SAWyer, S. "Protection versus Rights: the age of marriage versus the age of consent», The Lancet Child and Adolescent Health, april, vol. 3-4, 2019, pp. 274-280.

Potter, J. R., «Sex offenses», Maine Law Review, vol. 28-1, 1976, pp. 6595.

Prendergast, D., «Strict Liability and the Presumption of Mens Rea after CC v. Ireland», Irish Jurist, vol. 46, 2011, pp. 211-220.

- "The constitutionality of strict liability», Dublin University Law Journal, vOL. 33, 2011, pp. 285-318.

Regan, D. H., «Rewriting Doe v. Wade», Michigan Law Review, vol. 77, 1979, pp. 1569-1642.

Robinson, P. H., «The American Model Penal Code: A Brief Overview», New Criminal Law Review, Summer, vol. 10-3, 2007, pp. 319-341.

Robinson, P. H. / Williams, S. T., Mapping American Criminal Law. Variations across the 50 states, Praeger, California, 2018.

SANTEllo, J. S / SpindleR, E. / Moore, E., "Criminalizing sexuality or preventing child marriage: legal interventions and girls'empowerment», The Lancet Child and Adolescent Health, april, vol. 3-4, 2019, pp. 206208.

SAYre, F. B., «Public Welfare Offenses», Columbia Law Review, vol. 33, 1933, pp. 55-88.

Schwartz, L. B., «The Model Penal Code: An invitation to Law Reform», American Bar Association Journal, vol. 49-5, may, 1963, pp. 447-455.

- «Morals offenses and the Model Penal Code», Columbia Law Review, vol. 63-4, april, 1963, pp. 669-686.

Stevenson, K., "It is what Girls of indifferent character do... Complications concerning the Legal age of consent in the light of R v. C (2011), Journal of Criminal Law, vol. 76, 2012, pp. 130-139.

Stone, D. G., «The Model Penal Code in Idaho», Idaho Law Review, vol. 8-2, spring, 1972, pp. 219-288.

Stone, G. R. / Seidman, L.M. / Sunstein, C.R. / Tushnet, M.v. / Karlan, P.s., Constitutional Law, eight edition, Aspen Publishers, New York, 2018.

Tewksbury, R. / Jennings, W.g. / Zgoba, K. M., "A longitudinal examination of the sex offender recidivism prior to and following the implementation of SORN», Behavioral Sciences and the Law, vol. 30, 2017, pp. 308-328.

VARELA, L., «Strict liability como forma de imputación jurídico penal», Indret, 3, 2012, pp. 1-26.

V.AA., Víctimas de delitos: Modelos de actuación integral, Valencia, Tirant lo blanch, 2020, en prensa. 
Walkover, A., "The Infancy Defense in the New Juvenile Court», University of California Law Review, vol. 31, 1984, pp. 509-562.

Wasserstrom, R. A., "Strict liability in the Criminal Law», Stanford Law Review, vol. 12, 1959-1960, pp. 731-745.

WeEks, J., Sex, Politics and Society: the regulation of sexuality since 1800, $3^{\text {rd }}$ Edition, Routledge, New York, 2012. 